A RTIGOS TraduzIDOS/
TrRANSLATED A RTICLES 


\title{
OS DESAFIOS DE TRADUZIR FLAUBERT E ZOLA NA INGLATERRA VITORIANA ${ }^{1}$
}

\author{
Denise Merkle* \\ Université de Moncton, Canadá \\ Tradução de: \\ Aída Carla Rangel de Sousa** \\ Universidade Federal de Santa Catarina
}

Resumo: Na era vitoriana tardia, o campo da publicação, dividido entre público (circulating libraries, como a Mudie's Select Library) e privado (sociedades literárias secretas, como The Lutetian Society), estava no centro de profundas transformações sociais relacionadas à alfabetização. A estrutura hierárquica do campo revela o grau com o qual o discurso era tradicionalmente controlado na Grã-Bretanha, alinhado com a rígida estrutura de classes do país. Esta realidade marca um nítido contraste com

\footnotetext{
* Aída Carla Rangel de Sousa, tradutora deste artigo, possui bacharelado em Língua e literatura francesas pela Université de Paris III (Sorbonne Nouvelle) e mestrado em Estudos da Linguagem pela Universidade Federal do Rio Grande do Norte. Atualmente é doutoranda no Programa de Pós-Graduação em Estudos da Tradução (PGET) na Universidade Federal de Santa Catarina. Florianópolis, Santa Catarina, Brasil. E-mail:aidacarlarangel@gmail.com

** Denise Merkle possui bacharelado em Estudos Franceses pela York University de Toronto e mestrado em Estudos da Tradução pela Universidade de Montréal. Doutourou-se em Estudos Franceses pela Queen's University em Ontario, Canadá. Atualmente é professora titular em Estudos da Tradução da Université de Moncton, Canadá. Foi presidente da Associação Canadense de Tradutologia entre 2001 e 2004. É membro do comité de redação do periódico TTR (Traduction, Terminologie, Rédaction). Seus temas de pesquisa incluem tradução literária, tradução e interculturalidade, tradução e recepção, história da tradução, censura, reescrita e tradução. Moncton, New Brunswick, Canadá. E-mail:denise.merkle@umoncton.ca
} 
a visão geralmente aceita de que a Grã-Bretanha representa historicamente um modelo de livre expressão e de valores democráticos. O presente artigo explica que a maioria de moral burguesa, preocupada em proteger a integridade moral dos novos leitores alfabetizados da classe trabalhadora e das mulheres leitoras de todas as classes desejava dominar o flagelo da pornografia, com a crença de ser promovida por estrangeiros libertinos e aristocratas britânicos. Com o intuito de evitar perseguição, editores e tradutores precisavam considerar não somente padrões de expectativas do leitor, mas também as restrições discursivas alinhadas com os valores vitorianos. Um exemplo de editor que superestimou o grau de liberdade de expressão foi Henry Vizetelly, que tentou abastecer as classes trabalhadoras e as mulheres leitoras com traduções de trabalhos de Zola e Flaubert. Madame Bovary não foi banido pelas autoridades, ao passo que muitos romances de Zola o foram.

Palavras-chave: Henry Vizetelly. Émile Zola. Gustave Flaubert. Recepção vitoriana. Censura estrutural.

\title{
THE ISSUES OF TRANSLATING FLAUBERT AND ZOLA IN VICTORIAN ENGLAND
}

\begin{abstract}
The late-Victorian two-tier public (circulating libraries, e.g., Mudie's Select Library) and private (secret literary societies, e.g. The Lutetian Society) publishing field was at the centre of profound social transformations tied to literacy. The hierarchical structure of the field reveals the degree to which speech has traditionally been controlled in Britain, in alignment with the country's rigid class structure. This reality marks a sharp contrast with the generally held view that Great Britain has historically been a model of free speech and democratic values. The article explains that the bourgeoning moral majority preoccupied with protecting the moral integrity of newly literate working class readers and women readers of all classes wished to quell the perceived scourge of pornography, believed to be promoted by dissolute foreigners and British aristocrats. In order to avoid prosecution, editors and translators needed to consider not only patterns of reader expectations, but also the discursive constraints that aligned with Victorian values. An example of an editor who overestimated the degree of freedom of expression was Henry Vizetelly, who attempted to provide working class and female readers with translations of Zola's and Flaubert's works. While Madame Bovary was not banned by the courts, many of Zola's novels were.
\end{abstract}

Keywords: Henry Vizetelly, Émile Zola, Gustave Flaubert, Victorian reception, structural censorship. 
"[...] entre nós, estou convencido de que os ingleses têm contra meus romances grandes reservas $[\ldots]$. Além disso, fui bem mais celebrado na Inglaterra do que tenho sido lido ou compreendido". Émile Zola, 1893².

Historicamente o Reino Unido é considerado como uma das nações de maior vanguarda em matéria de liberdades democráticas, precisamente em relação à liberdade de expressão, "tradicionalmente apresentada como um valor fundamental ${ }^{3 "}$. Entretanto, ele fixou limites quando o bem-estar da nação estava em jogo. De fato, o governo britânico e os cidadãos colocaram em prática, em diferentes momentos, formas de entrave à liberdade de expressão, inclusive a censura, em um "espaço no qual ocorriam negociações entre indivíduos ou grupos a respeito de práticas e de discursos políticos, sociais ou culturais" ". Em A Long Time Burning, Donald Thomas argumenta de maneira convincente que os britânicos jamais usufruíram de uma liberdade de expressão absoluta ${ }^{5}$.

A era vitoriana fornece casos de entraves à liberdade de expressão resultantes de tensões entre poder, conhecimento e sexualidade que o trabalho pioneiro de Michel Foucault ${ }^{6}$ ajuda a compreender. Esses casos permitem ilustrar como a cultura de recepção em plena transformação sociocultural, que é aqui o Reino Unido vitoriano, recebe no espaço de encontro que é a tradução o estrangeiro tal como veiculado nos escritos de Gustave Flaubert e de Émile Zola; escritos esses que tentam penetrar no interior de seu espaço sociocultural-político. Basta dizer que a tradução de suas obras foi objeto de controvérsias durante este período. No presente artigo, daremos exemplos de resistência e de engajamento ${ }^{7}$ da parte de alguns tradutores vitorianos das obras de Flaubert e de Zola. Iniciemos, em primeiro lugar, por alguns fatos históricos a fim de ilustrar o contexto da atividade tradutória e situar a recepção vitoriana das obras neste estudo. 


\section{Alguns fatos históricos}

Desde 1792, cabe a um júri (a consciência do público) determinar a culpabilidade de um acusado. O júri deverá então, no século XIX, decidir as questões de difamação criminal. A lei sobre a difamação criminal assegura o sucesso dos processos judiciais contra toda obra julgada obscena porque trata de paixão sexual, por exemplo, e à qual o grande público (ou seja, as mulheres, as crianças, os "novos leitores ${ }^{8}$ ") tem acesso. No entanto, a tarefa de definir a obscenidade compete ao tribunal. O Ato de Publicações Obscenas de 1857 vai mais adiante e autoriza a polícia a submeter os livros destinados ao grande público aos juízes locais com o intuito de tê -los confiscados, depois destruídos por causa de obscenidade. Em 1868, o primeiro presidente da Corte de apelação Cockburn, no caso de $R$. V. Hicklin, deixa uma fórmula afirmando que a prova da obscenidade se encontra na tendência a depravar e a corromper o leitor ou a leitora ${ }^{9}$. Acredita-se que os novos leitores precisam da proteção concedida por uma lei ${ }^{10}$ que os defendam da literatura perniciosa, como as obras controversas de Flaubert, de Zola e de Maupassant em tradução ${ }^{11}$.

A revolução francesa de 1789 - com os escritos de Thomas Paine - e a de 1830 , em conjunto com a instrução das classes inferiores, provocam uma censura mais severa durante o século XIX. A alfabetização dessas classes resulta do Ato Educacional de 1870 e dos progressos tecnológicos que permitem uma difusão mais rápida e maior da literatura destinada ao mercado de massa. A instrução geral vê-se acompanhada do nascimento de ligas de moralidade, e os moralistas guiados pelo "moralismo da pequena burguesia ${ }^{12}$ " se atribuem a responsabilidade de proteger a classe trabalhadora e a classe média das "transgressões simbólicas ${ }^{13}$ " que reinam no domínio privado das sociedades literárias e científicas secretas. Os moralistas, geralmente advindos da pequena burguesia, sofrem de uma "tensão virtuísta", para retomar a fórmula de Pierre Bourdieu, e de uma "insegurança profunda", algo que os encorajava "à fantasia da $<$ pornocracia' ${ }^{\prime 4}$ ". O Parlamento conta com os moralistas 
para processar a literatura perniciosa em justiça, e estes últimos não o decepcionam.

Desde 1880, a polícia e o ensino obrigatório substituem os organismos religiosos como garantia da moralidade pública. Além disso, o Parlamento e o sistema judiciário enfrentam os problemas sociais que a polícia e o ensino obrigatório não conseguem eliminar ${ }^{15}$. Como prova, o relatório dos debates da câmara de deputados sobre os efeitos nocivos da literatura perniciosa sobre a nação britânica de 8 de maio de 1888 relata que o deputado do Leicestershire se pronuncia a favor da censura da literatura perniciosa, na qual se inclui um bom número de traduções, pois ele crê que ela pode fomentar os sentimentos revolucionários na população vulnerável - os novos leitores - fervilhamentos que começam a ser ouvidos ${ }^{16}$. É possível afirmar que o Parlamento deseja proteger a estabilidade moral e política, assim como a integridade da nação, e não hesita em apelar para a censura.

A vigilância do Parlamento durante os anos 1880 se explica da seguinte maneira. A partir de 1865 , a sociedade vitoriana se democratiza. Em razão disso, a classe dominante encontra-se na defensiva. A taxa de analfabetismo passa de 30 por cento em 1851 a 5 por cento em 1892, e os editores inovadores tais como Henry Vizetelly, que se afasta do sistema de gabinetes de leitura* ou das bibliotecas de empréstimo [circulating librairies à la Mudie's Circulating ou Select Library], publicam romances sensacionalistas $^{* *}$ traduzidos em apenas um volume e a bom preço. Os novos leitores podem comprar livros de agora em diante. No dia 16 de dezembro de 1884, James Davis escreve que como os escritores devem apenas lançar no mercado a um preço baixo os livros que o público demanda, eles não precisarão mais de bibliotecas de empréstimos $^{17}$, instituição que descarta todo título cujo teor moral é suspeito. Se os escritores desejam que as bibliotecas incluam as obras em listas de livros disponíveis para empréstimo, eles se veem obrigados a ceder às restrições impostas pelas bibliotecas, enquanto que os editores inovadores, como Vizetelly, os liberam dessas restrições. Esta revolução do mundo da edição provoca uma reação 
nos deputados, responsáveis por assegurar a ordem social, e nos moralistas $^{18}$. Entretanto, o Parlamento prefere que os indivíduos, inclusive os moralistas, processem os autores cuja obra for julgada obscena, ou o editor, quando se tratar de uma tradução.

Se remontarmos ao século XVIII, notamos que David Hume critica em 1777 a "liberdade de imprensa ilimitada"19" na Grã-Bretanha. Hume expressa aqui o receio da massa, da revolução e do republicanismo que ele compartilha com um bom número de seus compatriotas "porta-vozes autorizados ${ }^{20}$ ". Um século mais tarde, a recepção vitoriana dos produtos literários franceses, a título de exemplo, que reivindicam a reforma social, o anticlericalismo ou o republicanismo permanece fundamentalmente problemática. O deputado Samuel Smith insiste sobre a responsabilidade das classes superiores de se comportar como um modelo de imitação, inclusive em suas leituras. No entanto, é preciso lembrar que a literatura obscena, precisamente a pornografia ${ }^{21}$, sempre esteve à disposição dos membros das classes superiores, um exemplo por excelência do "efeito de terceira pessoa ${ }^{22}$ ". O que irrita tanto essas classes ao final do século XIX é que, de repente, as classes inferiores, que antes não tinham acesso, podem buscá-la abertamente e a baixo preço de agora em diante. Como maneira de manter a ordem tradicional e de assegurar o lugar privilegiado da elite, todo comportamento que não continua nos limites do decoro deve permanecer no domínio privado ${ }^{23}$. Em conformidade com o pensamento de Foucault, as diversas instituições - as bibliotecas de empréstimo, o sistema jurídico, o Parlamento, as ligas de moralidade - não podem impedir a difusão da literatura erótica, que floresce nessa época ${ }^{24}$, ainda que clandestina. Eis um campo de edição dividido: a edição pública (bibliotecas de empréstimo) e a edição privada (sociedades literárias secretas). Examinemos de perto a reação do campo de edição a um empreendedor como Henry Vizetelly, que ali tentou conquistar uma posição. 


\section{Vizetelly \& Company, e os romances escandalosos de Zola e de Flaubert}

\section{a. Zola}

Em seu livro Garden of Zola (1978), Graham King previne o leitor anglófono da sofrível qualidade das traduções em inglês dos romances de Zola. Na verdade, ele consagra um capítulo inteiro ao estudo dos valores vitorianos, à influência desses valores sobre a criação literária e sobre a tradução, com ênfase na influência de Thomas Bowdler. No prefácio de The Family Shakespeare, Bowdler escreve que ele suprimiu "everything that would raise a blush on the cheeks of modesty ${ }^{25}$ (tudo aquilo que poderia fazer corar a face da modéstia)". Ele morre em 1825 e seus discípulos, dentre os quais Charles Edward Mudie e W. H. Smith, continuam seu trabalho. Em 1842, Charles Edward Mudie abre a Select Library, a mais importante biblioteca de empréstimo ou "circulating library" que detém o monopólio da produção literária inglesa entre 1850 e 1890. Mudie e seu homólogo Smith selecionam todos os manuscritos que farão parte de sua coleção respectiva e exigem edições de três volumes ("triple-deckers") ${ }^{* * *}$ e de pequena tiragem com o intuito de tornar os preços proibitivos.

Editor de traduções inglesas de Zola e de Flaubert, dentre outros escritores franceses, e fundador-proprietário da editora Vizetelly, Henry Vizetelly desempenhou um papel importante na batalha contra as traduções de três volumes emprestadas pelas circulating libraries, único difusor respeitável de livros durante os anos 1880 . O contexto no qual ele pretende empreender as traduções de Zola, entre outros autores franceses, é o de uma sociedade hostil a tudo aquilo que não é decoroso, onde se vive sempre à sombra de Bowdler e onde a liga de moralidade (National Vigilance Association ou Associação de Vigilância Nacional), fundada em 1886 para promover a pureza social, usufrui de certo poder político. Esse pioneiro da edição moderna reaparece naquela sociedade opressiva após ter passado cerca de vinte anos em Paris (entre 1860 e 1880), onde 
ele era jornalista. É em Paris que ele encontra Zola em 1870 e, em 1877, ele é testemunha do escândalo causado por l'Assommoir (romance e peça) entre outras obras do mestre de Médan. Vizetelly rapidamente percebe que o sucesso desse escritor é "baseado no escândalo ${ }^{26 "}$ ". E ele espera que suas traduções renderão tanto quanto as obras originais ${ }^{27}$. Vizetelly \& Co. dá início à tradução dos romances de Zola antes da tradução dos romances de Flaubert.

O primeiro romance de Zola publicado na Grã-Bretanha em 1883, em uma tradução inglesa de Frank Belmond, foi The Ladies' Paradise [Au bonheur des dames]. As bibliotecas de empréstimo haviam recusado de estocar esse livro em três volumes, publicados pela editora Tinsely Brothers, que o achavam condenável no plano moral. Tinsley Brothers, um dos "porta-vozes autorizados ${ }^{28}$ " do discurso legítimo das classes médias, se equivocou sobre a recepção dessa tradução. Sem dúvida, esse triple-decker havia sido expurgado, mas ainda estava longe de reproduzir o "moralismo pequeno burguês ${ }^{29}$ ". Por conseguinte, a tradução não encontrou adeptos nas bibliotecas de empréstimo ${ }^{30}$. Finalmente, é Vizetelly \& Co. que a publica em 1886.

No seu retorno a Londres em 1880, e convencido da existência de um mercado de massa para essas traduções, Henry Vizetelly soube aproveitar a ocasião mesmo sabendo que as ligas de moralidade seguramente não desejavam que os "novos leitores" das classes trabalhadoras tivessem acesso às edições mais baratas. No entanto, os romances em versão original circulavam livremente, a fim de assegurar que somente as pessoas instruídas advindas geralmente das classes privilegiadas tivessem livre acesso aos romances estrangeiros, dentre os quais os de Zola e Flaubert. De sua parte, Vizetelly esperava que as traduções suscitassem o interesse de novos leitores e aumentassem suas receitas. Sua editora publicou romances traduzidos de Zola, como Nana em março de 1884, The 'Assommoir' [L'Assommoir] em julho de 1884, Piping Hot! [Pot-Bouille] em fevereiro de 1885 e Germinal em julho de 1885, entre outros títulos. Essas traduções, pelo menos, a princípio, não censuradas, eram escandalosas e destinadas à venda nos quiosques de livros. Os 
círculos literários estabelecidos, por sua vez, desqualificaram essas traduções. Devido ao grande sucesso desses romances na França, Vizetelly comprou os direitos autorais ingleses de todas as obras de Zola. Todavia, as traduções eram versões expurgadas do original, pois eram destinadas aos novos leitores, entre os quais reinava uma "estética dominada" ${ }^{1}$. O leitor britânico que lia essas obras traduzidas conhecia somente então um Zola à moda inglesa.

Foi Albert Vandam quem produziu a primeira tradução censurada de Germinal $^{32}$. O jornalista-tradutor havia levado em consideração o gosto do público britânico e praticou a autocensura. A tradução apareceu em folhetins no The People do dia 30 de novembro de 1884 ao dia 26 de abril de 1885 sob o título de Germinal, or Master and $\mathrm{Man}^{33}$. De acordo com diversos críticos, Vandam simplesmente não conseguiu reproduzir a intensidade da obra original: "São atenuados ou suprimidos na versão inglesa do romance as cenas da vida familiar mais íntimas, [a promiscuidade], a violência, certos discursos anticlericais e reflexões revolucionárias ${ }^{34}$ ". A exclusão da "representação de certas realidades ${ }^{35}$ " nos coloca diante de uma tradução que sujeita a arte de Zola à "disposição ética ${ }^{36}$ " burguesa, ou pelo menos pequena burguesa.

Henry Vizetelly comprou os direitos de reprodução e publicou em forma de livro uma versão mais completa de Germinal do que aquela publicada no The People. A publicidade no catálogo de Vizetelly \& Co. de abril de 1885 especifica que a tradução de Germinal assim como a de La Curée [The Rush for the Spoil] e também aquela de Thérèse Raquin estavam em preparação. O nome de Zola aparece frequentemente nos anúncios publicitários da editora Vizetelly, assim como nas páginas de The Bookseller. No mês de julho aparece a primeira edição inglesa não ilustrada de Germinal, or Master and Man: A Realistic Novel. O volume continha uma capa ilustrada, mostrando Maheu que abre sua camisa, descobrindo o peitoral diante das baionetas dos soldados que protegem a mina. Ao contrário das outras traduções publicadas pela editora Vizetelly, o aparecimento da edição não ilustrada, mais modesta, precedeu o aparecimento da edição ilustrada. 
No momento de sua publicação em 1887, la Terre provocou uma crítica geral bastante negativa na França. Os "Cinco", em seu Manifesto que se tornou famoso, escrevem: "a nota suja do romance estava mais exagerada, rebaixada a imundícies tão abjetas que, por alguns instantes, era como estar diante de uma coletânea de escatologia ${ }^{37}$ ". Apesar do escândalo francês, ou talvez por causa dele, Vizetelly manda fazer a tradução desse romance. Ao final de 1887, o primeiro tradutor recusou-se a terminar a tradução de $l a$ Terre devido à linguagem e um segundo reagiu da mesma maneira. Por esta razão Ernest Vizetelly, o filho de Henry, recomendou a supressão de certas passagens e a modificação do vocabulário. Em março de 1888, The Soil estava pronto para a impressão. Neste ínterim, a liga de moralidade havia solicitado o apoio do moralista William Stead, editor do Pall Mall Gazette, em sua campanha de censura das traduções publicadas pela Vizetelly \& Co. Em um artigo, Stead escreve que Vizetelly não tinha de maneira alguma tentado censurar os romances de Zola, ao que Vizetelly responde que nenhuma de suas traduções é uma reprodução fiel.

\section{b. Flaubert e Madame Bovary ${ }^{38}$}

Eleanor Marx faz suas primeiras traduções de textos políticos sob a direção de seu pai, Karl Marx. No momento de traduzir $M a$ dame Bovary ela termina sua tradução de L'Histoire de la commune de Lissagaray, e presta assistência na tradução do Capital $^{39}$. Uma motivação política e moral, assim como pecuniária (a tradução foi uma de suas profissões), a levou a traduzir Madame Bovary.

Eleanor Marx-Aveling ${ }^{40}$ não é conhecida como uma personagem literária, mas, na realidade, ela trabalhou bastante com literatura (em sentido amplo), tendo realizado um bom número de traduções a partir do francês (Madame Bovary e ensaios políticos), do norueguês (peças de Ibsen) e também do alemão (textos políti$\cos )^{41}$. Sua tradução de Madame Bovary é feita a partir da edição definitiva de 1873, que compreende o romance não censurado, a acusação, a defesa e o julgamento. Marx-Aveling trabalha nela 
a partir de novembro de 1885 e durante o primeiro trimestre de 1886. A tradução aparece no mês de agosto de 1886. Essa data coincide com a publicação de The Woman Question, ensaio que denuncia a situação das mulheres nas sociedades capitalistas. Contrariamente a Zola e suas trocas de correspondência com os Vizetelly, estando Flaubert falecido, a tradutora não podia escrever para ele pedindo sua colaboração. Após o processo de 1857, data em que o procurador imperial tentou vilipendiar o romance, Madame Bovary conhece um sucesso crescente, e alcança o status de obra-prima na França em reconhecimento de sua originalidade e de sua virtuosidade artísticas. Na Inglaterra, porém, Flaubert sofre da mesma má reputação que aquela atribuída a Maupassant e Zola. Mesmo Henry James que se revela, às vezes, generoso em seus elogios a Zola, torna-se mais circunspecto quando se trata de Madame Bovary ou da Éducation sentimentale de Flaubert ${ }^{42}$. Felizmente, Flaubert tem também seus defensores, dentre os quais Havelock Ellis, que ia solicitar, por intermédio de George Moore, a tradução de Madame Bovary para a conta de Vizetelly \&Co.

A tradutora manteve uma relação de amizade, graças ao interesse mútuo pelo teatro, com George Moore, cujos romances audaciosos ela admirava ${ }^{43}$. Ela escreveu para sua irmã, Laura Lafargue, que graças a Moore, ela obteve o contrato bem remunerado da tradução de Madame Bovary ${ }^{44}$. No dia 23 de abril de 1886, Marx-Aveling termina sua tradução e escreve novamente para Laura: "Terminei (Deus seja louvado!) minha tradução ... Foi um trabalho duro! Ela permanecerá por muito tempo, eu suponho[...], e estou trabalhando em uma 'Introdução' para ela" ${ }^{45}$. Mesmo sendo imperfeita segundo alguns, incluindo a tradutora, essa tradução permaneceu durante muito tempo a única versão inglesa disponível ${ }^{46}$.

Trata-se da primeira tradução da obra-prima de Flaubert a surgir na Inglaterra, como todas as traduções de Eleanor Marx-Aveling ${ }^{47}$. Em uma carta escrita em 1862, entretanto, Flaubert faz referência a uma tradução britânica "[f]eita sob meus olhos" e, segundo ele, "uma obra-prima ${ }^{48}$ ". Todavia, Flaubert não identifica nenhuma editora em Londres que aceite publicar a tradução; a no- 
toriedade negativa do processo público e tristemente conhecido de 1857, conduzido pelo procurador imperial, que acusava o romance e seu autor de ultraje à moralidade pública e à religião, certamente desencorajou os decorosos editores vitorianos.

Ora, para Marx-Aveling tratava-se de um contrato original, interessante no plano intelectual e político, além de rentável. Portanto, certamente não é por puro interesse pecuniário que ela tenha aceitado o contrato. Inicialmente, lembremos que ela é uma mulher com grandes interesses literários, que decide traduzir uma obra -prima literária, cuja originalidade e mérito eram reconhecidos na França desde essa época. Contudo, seu interesse não se encerra aí. Evidentemente, a filha de Karl Marx viu em Emma um exemplo comovente da desigualdade promovida pela sociedade em relação às mulheres e aceitou o trabalho com o objetivo de contestar as normas de moralidade de sua época ${ }^{49}$.

Eleanor escreve na introdução da tradução de maio de 1886 que, do fato que Flaubert era tão pouco conhecido na Inglaterra, uma introdução se fazia necessária a essa primeira tradução $0^{50}$. Ela continua que foi para Flaubert uma honra eterna que o romance tenha sido processado na justiça pelo governo de Napoleão III. O Sr. procurador, escreveu ela, encontra mais culpa na concepção do adultério do que na descrição minuciosa de uma doença moral, a saber a concupiscência (de que sofria também o cônjuge de Eleanor, Edward Aveling). As autoridades francesas acreditavam que Flaubert - assim como Zola, aliás - não intervinha o bastante em sua narrativa para condenar o comportamento de Emma e de outros personagens. Bem ao contrário, ele se contentou de observar e de constatar. Eleanor reage na introdução explicando que "a moralidade de fachada do advogado revolta ${ }^{51}$ ", em referência à hipocrisia dos tribunais. De acordo com a tradutora, Flaubert fornece um espelho dessa sociedade burguesa decadente, e é esse fato, mais do que o enredo de adultério do romance, que tanto escandalizou a sociedade francesa e que ia tanto escandalizar trinta anos mais tarde a sociedade inglesa. Eleanor simplesmente acredita ser natural que aqueles que reconhecem sua própria imagem estejam choca- 
$\operatorname{dos}^{52}$. No plano pessoal, Eleanor era fascinada pela personagem de Emma, mulher burguesa que se iludia e não era fiel a si mesma. A vida de Emma não tinha utilidade nem propósito. Ela não tinha nenhuma ocupação $0^{53}$.

O que dizer, então, da tradução? As marcas do "bowdlerismo" ali são mínimas (a tradutora escreve, por exemplo, "confinement"); não há cortes. Marx-Aveling escreve em sua "Introdução", "pelo menos... Eu não suprimi nem acrescentei uma linha, uma pala$v r a . .{ }^{54}$ ". É evidente que ela não respeitava a convenção social da época e colocava de lado os enunciados do Dr. Bowdler quando traduzia o romance. A tradutora afirma que sua tradução é integral, até mesmo literal, e não censurada. Ignora-se se ela fazia uma alusão indireta à expurgação feita nas traduções de Zola nesse momento pela editora Vizetelly, a mesma que publicou sua tradução.

Ora, pelo menos um crítico comentou a falta de discrição em sua tradução. Uma crítica publicada no The Athenaeum sublinha que a tradução: "não contém nenhuma frase bonita" e que ela foi realizada "com mais zelo do que discrição ${ }^{55 "}$. O autor do artigo questiona a fala não censurada de Marx-Aveling e o fato que a tradutora não denuncia em sua introdução o comportamento de Emma, personagem cujo comportamento chocou o leitor médio dos anos oitenta e que o leitor conservador achava condenável. Pelo contrário, Marx-Aveling mostra a compaixão por Emma. Não é de se espantar, então, que a tradução, assim como o original, encontrou a oposição por ultraje à moralidade na imprensa e em parte da liga de moralidade. Os defensores vitorianos da moralidade pública consideram Madame Bovary e Salammbô como pornográficos, mas não processam a última tradução. A Associação de Vigilância Nacional se contentou de investir contra Madame Bovary em $1888^{56}$.

$\mathrm{O}$ editor da coleção The Mermaid Series na qual apareceu $M a-$ dame Bovary, Havelock Ellis, no artigo sobre a vida de Eleanor Marx publicado em Adelphi, não elogia o mérito da tradução:

"Pedi a Eleanor para traduzir An Enemy of Society. [...] ela já havia realizado trabalho literário, notadamente a tradução 
de Madame Bovary de Flaubert, não exatamente um trabalho sem faltas, mas por muitos anos a única versão dessa obra-prima disponível aos leitores ingleses ${ }^{57}$ ".

Por outro lado, William Sharp, especialista da poesia britânica, francesa e germânica da época, considera essa tradução não somente como "fiel", mas também como "natural"5" e o original como intraduzível. Sobre este último ponto, ele concorda com a tradutora, que o considera "inimitável”. Porém, ele constata que Flaubert não tem nenhum interesse por aqueles que não sabem ler em francês, confirmando assim a convenção que somente as pessoas instruídas deviam e sabiam ler tais romances. É interessante notar que George Steiner sente a influência da era vitoriana na tradução, mesmo se ele parece não concordar com o a opinião de Sharp quanto ao "natural". Sobre isso ele escreve: "Lida atualmente, esta versão que muitas vezes peca na fineza, reergue-se graças a um perfume de época ${ }^{59}$ ", ainda que ele não forneça nenhuma prova textual para sustentar sua afirmação $0^{60}$.

\section{Henry Vizetelly diante dos tribunais}

Henry Vizetelly precisou comparecer duas vezes aos tribunais ${ }^{61}$. No dia 31 de outubro de 1888, aos 68 anos e com saúde precária, ele se encontrava em Old Bailey em Londres, para defender sua tradução de Nana, de Pot Bouille e de la Terre. O procurador, Sir Edward Clarke, leu algumas passagens de The Soil, que tratavam do acasalamento de um boi e de uma vaca, de estupro, de assassinato, de incesto, e assim por diante. Na nona passagem, o júri se recusou a ouvir o restante. Vizetelly finalmente declarouse culpado. Ele precisou pagar uma multa de 100 libras esterlinas e foi condenado a doze meses de prisão com pena suspensa. A reação dos jornais foi intensa e expressava uma tendência contra Vizetelly. Após o primeiro processo, Vizetelly \& Co. anuncia em janeiro de 1889 que Germinal, or Master and Man fará parte da 
lista de traduções que serão reimpressas com ilustrações originais, após revisão, e vendidas a baixo preço. Essa revisão corresponde, na verdade, à obrigação de uma segunda expurgação operada por Ernest Vizetelly. Do fato que a editora Vizetelly beirava a falência após o primeiro processo, baixar o preço devia assegurar a venda de grande número dessas traduções que preencheriam os cofres esvaziados pelo processo. O editor continuou então a vender os livros que, segundo ele, não foram citados no julgamento (na verdade, $\mathrm{o}$ julgamento foi muito vago).

Em 30 de maio de 1889, na corte criminal central de Londres, ocorreu um segundo processo de Henry Vizetelly. A liga de moralidade colocou novamente na lista de livros proibidos Madame Bovary, mas o júri recusou-se a processar o romance, pois receava perder a causa já que o livro começava a tornar-se reconhecido como uma obra-prima não somente na França, mas também na Inglaterra pela elite intelectual. A acusação pesava então sobre The Rush for the Spoil, The Fortune of the Rougons, Fat and Thin (Le Ventre de Paris), The Assommoir, Abbe Mouret's Transgression, His Excellency Eugene Rougon, How Jolly Life Is (La Joie de vivre) e Bel Ami (de Maupassant). É interessante constatar que a tradução de uma obra de Zola que se vê retirada da segunda lista de traduções visadas - a de Germinal - é aquela que apareceu inicialmente em The People, porta-voz da Igreja e do Estado, em outras palavras, porta-voz do discurso autorizado. Parece que foi o apoio conjunto do The People e do Globe que protegeram essa tradução. As outras traduções incriminadas desde o primeiro processo (Nana, Piping Hot ! et The Soil) oram naturalmente proibidas. Vizetelly declarou-se culpado por recomendação de seu advogado. O processo foi muito breve. Como o editor não estava em posição de pagar uma multa, ele foi condenado a três meses de prisão por recidiva. Dessa vez os jornais calaram-se. Pouco depois, Vizetelly \& Co. foi à falência.

Nem todos estavam a favor do julgamento contra Vizetelly \& Co. Na verdade, no dia 2 de novembro de 1888 surgem no The Star dois artigos ${ }^{62}$ que tratam do primeiro processo contra Vizetelly e 
que denunciam o julgamento. No primeiro intitulado "Vizetelly and Zola : The Paper Which First Introduced Zola to the English Masses (Vizetelly e Zola: O jornal que primeiro introduziu Zola às massas inglesas"), o editor responde a uma questão que trata do julgamento. Ele explica que não sabe exatamente quais títulos foram proibidos, devido aos relatórios contraditórios. Na realidade, o tribunal processou especialmente La Terre, mas o julgamento abrangeu diversos títulos. Vizetelly acrescenta que ele não conseguiu encontrar um bom advogado para defender sua causa, pois vários deles eram igualmente deputados no Parlamento e que eles temiam ofuscar os membros de suas respectivas circunscrições.

$\mathrm{O}$ segundo artigo trata-se de uma carta aberta assinada por "um escritor" [a novelist] e intitulada The Vizetelly Prosecution: To the Editor of 'The Star' (A Acusação Vizetelly: Ao Editor do 'The Star'). Trata-se de uma defesa em favor da liberdade de expressão e da liberdade de imprensa. $\mathrm{O}$ autor queria que as autoridades tivessem consciência de seus deveres e de suas responsabilidades enquanto cidadãos de um país democrático. Enfim, o autor sugere que a verdadeira questão que coloca Zola é a seguinte: um escritor moderno tem o direito de expor os males da sociedade? De sua parte, Vizetelly explicita que ele havia feito o possível para transformar os romances de Zola em "representação legítima" 63 . Assim, ele explica ao jornalista do Star de que havia tentado "vestir la Terre à inglesa" ${ }^{64}$. Paradoxalmente, esse esforço foi em vão e não reconhecido durante o primeiro processo.

Visando sempre um mercado de massa, Ernest Vizetelly vende em 1895 os direitos da tradução inglesa de Germinal, entre outros títulos de Zola, à editora Chatto \& Windus, que publicará em 1901 uma tradução ainda mais expurgada do que aquela que resulta na segunda censura de 1888 . É Ernest Vizetelly mesmo que fará a nova versão. Sobre esse assunto, ele escreve uma carta para Zola no dia 7 de janeiro de 1895 :

"Não há dúvida que eu tenho (juntamente com os senhores) direitos sobre La Terre e Germinal, e consequentemente 
minhas demandas [Ernest Vizetelly reivindica direitos da Lutetian Society] são bem fundadas. Quando esse assunto for resolvido, vou empenhar-me de lançar uma edição a preço baixo de Germinal, após ter edulcorado ou suprimido algumas passagens que possam criar problemas. Assim, poderemos fazer duas vezes mais dinheiro com esse livro ${ }^{65}$ ".

De fato, em 1894, Chatto \& Windus adquiriu os direitos ingleses de Ernest Vizetelly, que trabalhava lá e prosseguia a expurgação e a alteração de quinze traduções para não ofender o público (salvo, evidentemente, la Terre, Nana e Pot-Bouille que continuavam proibidos na Inglaterra). Ernest Vizetelly incluiu Germinal na lista das traduções inglesas e americanas que "figuram neste índice ${ }^{66}$ " em uma carta que ele escreve para Zola no dia 7 agosto de 1893. É interessante notar o número de exemplares de traduções vendidos na Grã-Bretanha até 1911: Nana 215.000 (contra 198.000 na França), Piping Hot ! 102.000 (95.000), Germinal 132.000 (110.000), The Soil $162.000(135.000)^{67}$. O número de exemplares de traduções vitorianas - frequentemente traduções proibidas - ultrapassa largamente o número de exemplares vendidos na França.

\section{Algumas palavras sobre a Société Lutétienne [The Lutetian Society ${ }^{68}$ ]}

Se, no domínio público do campo da literatura traduzida, uma língua polida era a norma discursiva, não havia restrições no domínio privado das sociedades literárias e eruditas secretas onde a "transgressão simbólica ${ }^{69}$ " reinava. No momento em que Henry Vizetelly era processado na justiça por ter publicado traduções obscenas, Richard F. Burton mandava publicar sob a proteção da sociedade literária secreta, mas inventada, a Kamashastra Society of London and Benares, 1.000 exemplares de sua tradução não censurada e erotizada, as Mille et une nuits [A Thousand Nights and a Night] vendida por assinatura. Além disso, o sistema sociocultural 
tolerava a livre difusão de livros escritos em língua estrangeira, pois apenas as pessoas educadas (aquelas que detêm o poder político) possuem acesso. Por outro lado, as autoridades vigiavam com menos rigor os supostos clássicos da literatura europeia mesmo em tradução, situação que Henry Bohn explora de maneira bem-sucedida em seus volumes "suplementares" [volumes extras] ${ }^{70}$. Zola também foi apreciado por uma sociedade literária secreta.

Durante a segunda semana de julho de 1894 surgiram nos jornais de Londres chamadas anunciando a publicação autorizada por Zola, de doze volumes dos Rougon-Macquart pela Lutetian Society, uma sociedade erudita e secreta ${ }^{71}$. A editora nova-iorquina Henry Holt \& Company, editora da Lutetian Society teria pedido em 05 de fevereiro de 1894 a Zola "a autorização de publicar uma edição de pouca tiragem de suas obras que tinham caído em domínio público - edição que devia ser lançada por assinatura, cada volume sendo cotado a um preço relativamente alto $^{72}$ ". A tiragem desses volumes se limitou a 310 exemplares. Ernest Vizetelly reuniu os folhetos dessa sociedade proveniente de Londres, Irlanda, Escócia... Parece não ter havido correspondência entre Zola e a Lutetian Society. Para as traduções em inglês, o escritor tratou apenas com a editora Henry Holt \& Company, além dos Vizetelly. Uma carta desse editor destinada a Zola na data de 8 de março o agradece de sua autorização para publicar uma nova tradução de seus romances ${ }^{73}$. A ligação entre o editor americano e a Lutetian Society permanece obscura.

Foi Alexander Teixeira de Mattos que dirigiu em Londres entre 1894 e 1895 a retradução de seis romances de Zola. Colaboraram também com o projeto: Arthur Symons (L'Assommoir), Ernest Dowson (La Terre), Victor Plarr (Nana) e Percy Pinkerton (Pot-Bouille). Teixeira de Mattos trabalhou na tradução de la Curée e contactou Havelock Ellis para a tradução deGerminal. Este último aceitou pois, como ele indica em sua introdução, ele precisava de dinheiro. Ellis havia trabalhado na edição dos anos 1880, especialmente enquanto diretor da série Mermaid de Vizetelly \& Co, mas ele nunca havia feito tradução. O escritor assinou um contrato 
no dia 15 de fevereiro de 1894, os co-signatários sendo Joseph Hannaford Bennet e Leonard Smithers, dois editores de Londres. Smithers, discípulo e colaborador de Burton, seguia as atividades da Lutetian Society ${ }^{74}$.

Havelock Ellis gostou de fazer a tradução e desenvolveu nessa ocasião mais estima pelo mestre de Médan. Na introdução à tradução, ele conta ter traduzido em voz alta e sua esposa era quem escrevia. Esta maneira de trabalhar o fez descobrir todos os mistérios da obra de Zola e o possibilitou interrogar-se sobre a estrutura do romance, o que - segundo ele - a simples leitura não permitia. Mesmo reconhecendo as falhas de sua trabalho, o (re)tradutor de Germinal se mostra convencido da importância do romance e alegra-se de haver produzido a única tradução inglesa não censurada, deste "grande afresco"75. Mas ele não fará outras traduções. Com efeito, todas as seis traduções produzidas pela Lutetian Society eram não censuradas.

\section{Considerações finais}

Após a adoção do Ato de Publicações Obscenas de Lord Campbell em 1857, uma série de processos - os de Hicklin (1868), de Bradlaugh e Besant (1877) e de Vizetelly (1888 e 1889) - apresenta a "margem [margin] ${ }^{76 "}$ reduzida dos editores que trabalham na esfera pública e fornecem os precedentes cuja influência iria ser sentida até a segunda metade do século XX.

A gênese da tradução das obras de Flaubert e, sobretudo aquelas de Zola, na Inglaterra entre 1884 e 1895 inscreve-se em um campo de tensões entre a esfera pública, onde reinava um conformismo ético sustentando pelos moralistas burgueses e pequenos burgueses conservadores, e a esfera privada, onde os "libertinos" das classes superiores buscavam fazer valer a alteridade moral e a arte pela arte. Com efeito, um sistema de edição desigual é uma manifestação da censura estrutural que reproduz globalmente a estrutura social (os privilégios e os outros) $)^{77}$. As obras conformistas 
são publicadas na esfera pública, enquanto as obras controversas (por exemplo, as traduções não censuradas dos romances proibidos de Zola) são publicadas no privado.

Os editores operando na esfera pública podem ser acusados de obscenidade, enquanto os editores que operam na esfera privada (sociedades secretas que vendem suas obras aos "membros" e participantes) estão ao abrigo da lei. Graças às normas respeitadas e aos tabus não transgredidos no século XIX - pelo menos pela maioria da população britânica -, a autocensura sucede a censura na tradução de textos que visam o grande público, como por exemplo, The Ladies Paradise produzida por Tinsley Brothers e a tradução de Germinal produzida por The People. As obras expurgadas com uma tendência didática, destinadas às mulheres e às crianças ( $\mathrm{p}$. ex., a tradução das Mille et une produzida por Isabelle Burton ${ }^{78}$ nos contos de Hans Christian Anderson ${ }^{79}$ ) e às classes trabalhadoras (as traduções de Flaubert e de Zola publicadas pela editora Vizetelly), são depuradas com o intuito de fornecer modelos de expressão autorizados. De qualquer modo, mesmo vestidos à inglesa, Nana, Piping Hot e The Soil não estavam ao abrigo da censura. E se não se ousou proibir a tradução de Madame Bovary, é preciso esperar até os anos 1950 antes que o Reino Unido remova a proibição de venda dos três romances traduzidos de Zola.

\section{Notas}

1. O artigo, escrito originalmente em francês, e sua tradução para o português são inéditos.

2. Em Lethbridge R., "Zola and England", Bulletin of the Emile Zola Society, $\mathrm{n}^{\circ}$ 10 (Abril) 1993, pp. 3-13, p. 5. 
3. Cloarec N.; É. Dardenne, "Censorship v. Freedom of Speech in Englishspeaking Countries. Cultural, Political and Historical Pespectives “, Revue LISA/ LISA-ejournal [], vol. XI, nº 1, 2013. Disponível em 30 de maio 2013. Acessado em 04 de julho de 2014.

\section{Ibid.}

5. Thomas D., A Long Time Burning: The History of Literary Censorship in England, London, Routledge et Kegan Paul Ltd., 1969.

6. Cf. Foucault M., "L'Occident et la vérité du sexe", Le Monde, $\mathrm{n}^{\circ}$ 9885, 5 novembre 1976, p. 24. (http://1libertaire.free.fr/MFoucault218.html). Acessado em 4 de julho de 2014.

"Tocamos em um problema de ordem mais geral, que precisa ser tratado enquanto contraponto na história da sexualidade, o problema do poder. De maneira espontânea, ao se falar de poder, iremos concebê-lo como lei, como interdito, como proibição e repressão. E estamos completamente desarmados quando se trata de segui-lo em seus mecanismos e seus efeitos positivos. Um modelo jurídico pesa sobre as análises do poder, dando um privilégio absoluto à forma da lei. Seria preciso escrever uma história da sexualidade que não fosse vinculada à ideia de um poder-repressão, de um poder-censura, mas à ideia de um poder-incitação, de um podersaber. Seria preciso tentar afastar o regime de coerção, de prazer e de discurso que não é inibidor, mas constitutivo desse território complexo que é a sexualidade."

7. Cf., por exemplo, Simon S. (dir.), Numéro thématique : "Traduction engagée/ Translation and Social Activism", TTR, vol. 18, $\mathrm{n}^{\circ}$ 2, 2005, Tymoczko M. (dir.), Translation, Resistance, Activism, Amherst, MA, University of Massachusetts Press, 2010, et Tymoczko M. et E. Gentzler (dir.), Translation and Power, Amherst et Boston, University of Massachusetts Press, 2002.

8. Esse novos leitores provem das classes trabalhadoras.

9. Cf. Robertson G., Q.C., Freedom, the Individual and the Law, London, Penguin, 1989, p. 180, que cita Cockburn: "Acredito que o teste de obscenidade determina se a tendência da matéria acusada de obscenidade é depravar e corromper aqueles cujas mentes estão abertas a essas influências imorais, e nas mãos de quem uma publicação deste porte pode cair”. 
10. Ibid., p. 180-181.

11. Merkle D., "Émile Zola devant la censure britannique", TTR, vol. 7, $\mathrm{n}^{\circ} 1$, 1994, p. 77-91.

12. Bourdieu P., La distinction, Paris, Éditions de Minuit, 1979, p. 49.

13. Ibid.

14. Ibid., p. 50

15. Ibid., p. 142.

16. (The) National Vigilance Association (NVA), Pernicious Literature. Debate in the House of Commons. Trial and Conviction for Sale of Zola's Novels. With Opinions of the Press, Strand, London, The National Vigilance Association, 1889 , p. 11.

17. Coustillas P. (dir. e intro.), Literature at Nurse, or Circulating Morals: A Polemic on Victorian Censorship, Sussex, The Harvester Press Limited, 1976, p. 48.

18. Merkle D., "Vizetelly \& Company as (ex)Change agent: Towards the Modernization of the British Publishing Industry", J. Milton et P. Bandia (dirs.), Agents of Translation, Amsterdam et Philadelphia, John Benjamins, 2009, p. 85-106.

19. Thomas D., op cit., p. 2.

20. Bourdieu P., Ce que parler veut dire, Paris, Librairie Arthème Fayard, 1982, p. 69.

21. Os romances de Zola e Flaubert, por exemplo, são considerados obscenos ou mesmo pornográficos. 
22. O'Sullivan C., "Margin and the Third-person Effect in Bohn's Extra Volumes", D. Merkle, C. O'Sullivan, L. van Doorslaer et M. Wolf (dir.), The Power of the Pen: Translation and Censorship in Nineteenth-century Europe, Wien et Münster, Lit Verlag, 2010, p. 119-142.

23. Cf., por exemplo, Merkle D., op. cit., 1994.

24. Cf. Colligan C., "Obscenity and Empire: England's Obscene Print Culture in the Nineteenth Century" [thèse inédite], Kingston $(\mathrm{ON})$, Queen's University, 2002, et Mullin K., "Pernicious Literature: Vigilance in the Age of Zola (18861899)", D. Bradshaw et R. Potter (dir.), Prudes on the Prowl: Fiction and Obscenity in England, 1850 to the Present, Oxford, Oxford University Press, 2013, pp. 30-51.

25. King G., Garden of Zola, New York, Barnes \& Noble, 1978, p. 228. King reproduit le principe qu'énonce Bowdler en 1823 : "Se qualquer palavra ou expressão é de natureza tal que a primeira impressão que ela estimula é a de obscenidade, então aquela palavra não deve ser pronunciada, escrita ou impressa. E se impressa, deve ser apagada" (ibid.).

26. Pagès A., La bataille littéraire, Paris, Librairie Séguier, 1989, p. 13.

27. Cf. Merkle D., op. cit., 1994.

28. Bourdieu P., op. cit., 1982, p. 69.

29. Bourdieu P., op. cit., 1979, p. 49.

30. Merkle D., "Germinal en Grande-Bretagne de 1884 à 1895 : de l'esthétique dominée à l'esthétique dominante", Cahiers naturalistes, nº 81, 2007, pp. 198-199.

31. A fórmula pertence a P. Bourdieu, op. cit., 1979, p. 49.

32. Bakker B., Correspondance, tome V 1884-1886, Montréal, Presses de l'Université de Montréal et Paris, CNRS, 1985, p. 186, lettre 121, note 2 : “[O] texto [...] foi submetido a cortes semelhantes aos da edição alemã." 
33. Para mais detalhes sobre o percurso de Germinal na Grã-Bretanha de 1884 a 1895, Cf. Merkle, op. cit., 2007.

34. Ibid., p. 204.

35. Bourdieu P., op. cit., 1979, p. 49.

36. Ibid.

37. Bonnetain P., Rosny J.-H., Descaves L., Marguerite P., Guiches G., Manifeste des Cinq : La Terre, à Émile Zola. (http://www.berlol.net/chrono/ des5.htm).

38. Já que a tradução de Salammbô produzida por J. S. Chartres para a conta de Vizetelly \& Co (1886) não foi perseguida pela liga de moralidade, não a discutimos neste artigo. Para saber mais sobre as traduções concorrentes desta obras, remetemos a Atkinson J., "'The Most Thrilling and Fascinating Book of the Century': Marketing Gustave Flaubert in Late Nineteenth-Century England », K. MacDonald et C. Singer (dir.), Transitions in Middlebrow Writing, 1880-1930, Houndmills (Basingstoke, Hampshire), Palgrave MacMillan, 2015, p. 163-182 e a Merkle D., «M. French Sheldon, Translator of Gustave Flaubert's Salammbô: Transauthorship and the Mechanics of Censorship in Late-Victorian Britain ", D. Merkle, C. O'Sullivan, L. van Doorslaer et M. Wolf (dir.), The Power of the Pen: Translation and Censorship in Nineteenth-century Europe, Wien et Münster, Lit Verlag, 2010, p. 97-118.

39. Tsuzuki C., The Life of Eleanor Marx 1855-1898, London, Oxford University Press, 1967, p. 113.

40. Seu cônjuge de fato é Edward Aveling.

41. Simon S., Gender in Translation, Cultural Identity and the Politics of Transmission, London et New York, Routledge, 1996, p. 67.

42. Cf. James H., "Gustave Flaubert", Madame Bovary, London, Appleton \& Company, 1902, p. v-xliii :

H. James escreve sobre Madame Bovary e Éducation sentimentale : "Nossa objeção é que Emma Bovary, apesar da natureza de sua 
consciência e apesar de ela refletir tanto de seu criador, trata-se realmente de um caso muito pequeno. Por que Flaubert escolheu, como canais especiais da vida que ele propôs retratar, espécimes tão inferiores e, no caso de Frédéric, tão desprezíveis? ...] mas se ele não imaginava nada melhor para seu objetivo do que uma tal heroína e um tal herói, ambos espelhos e registros tão limitados, somos forçados a acreditar que tenha sido por um defeito em seu intelecto."

e "Émile Zola" (1903), Veeder e Griffin (dir.), The Art of Criticism: Henry James on the Theory and the Practice of Fiction, Chicago, University of Chicago Press, 1986, p. 423-458.

43. Tsuzuki C., op. cit., p. 166-167. Um romance controverso é A Mummer's Wife.

44. Cf. Kapp Y., Eleanor Marx: Volume II, The Crowded Years (1884-1898), London, Lawrence and Wishart, 1976, p. 95 et Florence R., Marx's Daughters, New York, Dial Press, 1975, p. 41.

45. Kapp Y., op. cit., p. 97.

46. Para saber mais sobre as retraduções britânicas de Madame Bovary, consultar Deane S., "Flaubert and the retranslation of Madame Bovary ", Flaubert, Revue critique et génétique [Online], vol. 6, 2011. mis en ligne le 30 janvier 2012. (http://flaubert.revues.org/1538) Page consultée le 28 juillet 2015.

47. Ibid., p. 99. Florence (op. cit., p. 42) acredita também que a tradução de Eleanor foi a primeira tradução desse romance a ser publicada na Inglaterra.

48. Flaubert é citado por Kapp Y., op. cit., p. 97.

49. Simon, op. cit., 1996, p. 67.

50. Marx-Aveling E., "Introduction", Madame Bovary, tradução de E. MarxAveling, London, Vizetelly \& Co, 1886, p. ix.

51. Ibid., p. xv. 
52. Tsuzuki, op. cit., p. 166.

\section{Ibid.}

54. Marx-Aveling E., op cit., p. xxii.

55. Citado por Kapp Y, op. cit. p. 97.

56. O que teria chocado o leitor conservador é o comportamento do senhor Guillaumin (exemplos sublinhados duas vezes), ao passo que esse comportamento masculino reforça a ideologia marxista de Eleanor no que se refere ao valor da mulher como objeto de troca. A tradutora não quer poupar o leitor dessa descrição minuciosa do materialismo grosseiro do sistema capitalista.

57. Ellis H., “Eleanor Marx II”, Adelphi, 11, 1 outubro 1935, p. 34.

58. Kapp Y., op. cit., p. 98 reproduz um trecho da crítica publicada por W. Sharp em The Academy do dia 25 de setembro de 1886:

"Flaubert é, preeminentemente, um escritor intraduzível. Ele é como a Sra.Aveling declara apropriadamente no prefácio, inimitável... e ele é intraduzível, não porque ele escreve um francês perfeito, mas porque as palavras são para ele absolutamente significativas - possuem um peso, uma urgência de revelação, por assim dizer, que é praticamente necessário além do poder do tradutor reproduzir em uma língua estrangeira. É razoavelmente certo que nenhuma versão inglesa dos romances de Flaubert irá reproduzir adequadamente o charme do estilo de mestre. É preciso se contentar com a tradução que é ao mesmo tempo fiel e inteiramente natural. A Sra. Aveling merece crédito pela maneira como cumpriu sua tarefa. E se falhamos reiteradamente em discernir Flaubert na versão anterior a nós, não é bem culpa dela."

59. Steiner G., Après Babel: Une poétique du dire et de la traduction, traduction de L. Lotringer, Paris, Albin Michel, 1978, p. 347. O flaubertiano G. Falconer ("Madame Bovary and the Translators", P. Bhatt (dir.), Significations: Essays in honour of Henry Schogt, Toronto, Canadian Scholars Press, 1997, 41-50), considera a tradução de Marx-Aveling muito moderna. Ele não a considera de maneira alguma como uma reescritura. Falconer reconhece que Eleanor seguiu o texto de partida (embora veja aí algo de positivo) e, deliberadamente ou por inadvertência, 
reproduz assim a desordem textual de Flaubert. Ele reconhece igualmente que ela fornece um modelo de tradução que seus sucessores imitaram em seguida. Tratase, portanto, de uma primeira tradução. Considerando a "modernidade" de sua tradução, não é de se espantar que ela seja incomum comparativamente a outras traduções publicadas pela Vizetelly \& Co. durante a mesma década.

60. Simon S., op. cit., p. 67. Y. Kapp (op. cit., p. 99) critica as fraquezas de uma tradução que contém galicismos incompreensíveis (de acordo com Kapp, atribuídos a Paul Lafargue que nem sempre entendia o inglês e que, então, fornecia respostas erradas às questões colocadas por sua cunhada), e que é trufada de pequenas falhas.

61. Cf. Merkle, op. cit., 1994, pp. 81-82; 2007, pp. 201-205, para mais detalhes.

62. Cf. Ibid., 2007, pp. 201-204.

63. Ibid.

64. Anonyme, "Vizetelly and Zola : The Paper Which First Introduced Zola to the English Masses", Star (2 November), 1888, p. 2.

65. Speirs D. et Portebois Y., Mon cher Maître, lettres d'Ernest Vizetelly à Émile Zola, Montréal, les Presses de l’Université de Montréal, 2002, p. 142, lettre 46.

66. Ibid., p. 95, lettre 20 .

67. King G., op. cit., p. 427.

68. Para mais detalhes, consultar Merkle D., "Secret Literary Societies in Late Victorian England", M. Tymoczko (dir.), Translation, Resistance, Activism, Amherst et Boston, University of Massachussets Press, 2010, p. 108-128 et Merkle D., "The Lutetian Society", TTR, vol. 16, n 2, 2003, pp. 73-101.

69. Bourdieu P., op. cit., 1979, p. 50.

70. O'Sullivan C., op. cit. 
71. Speirs D. et Portebois Y., op cit., p. 129, carta 40, datada de 11 de julho de 1894. O promotor parece ter sido Jean de Mattos, domiciliado em Paris.

72. Ibid., p. 140 , carta 46. Cf. também, p. 131 , carta 40, nota 1 .

73. Ibid., p. 131, carta 40, nota 1.

74. Smithers fundou em 1896 o periódico The Savoy, cujo editor fundador era Arthur Symons, um dos tradutores da Lutetian Society. No Publisher to the Decadents, (Pennsylvania Park, The Pennsylvania State University Press, 2000), J. G. Nelson afirma que Leonard Smithers era o verdadeiro dirigente da Lutetian Society, assistido pelo tradutor e jornalista Alexander Teixeira de Mattos, um de seus amigos. Este último casou-se com Lily Wilde, a viúva do irmão de Oscar Wilde. Leonard Smithers foi o único editor londoniano a ousar publicar as obras de Wilde (p. 95).

75. Ellis H., "Introduction”, Germinal, London, J. M. Dent \& Sons Ltd, 1933 : "É [...] uma satisfação para mim saber que fui responsável, mesmo que inadequadamente, pela única versão inglesa completa dessa maravilhosa obra, "um grande afresco" como Zola mesmo a chamava, um excelente épico em prosa, como pareceu a alguns, digno de comparar com os grandes épicos em verso dos antigos" (p. viii).

76. O'Sullivan C., "Margin and the third-person effect”, op. cit., p. 120. Bem retomada por O'Sullivan, a noção de “margem” é primeiramente concebida por A. Lefevere ("Translations and Other Ways in Which One Literature Refracts Another", Symposium, vol. 38, n ${ }^{\circ}$ 2, 1984, p. 128).

"[...] você pode, em teoria, dizer qualquer coisa que queira, de qualquer maneira. Na prática, porém, se você deseja ser ouvido, terá de dizer com certa margem, e essa margem, que cresce mais ou menos na história, é projetada por aqueles que eu chamo de patrões, ...] todos os poderes que (por caso) são capazes de encarregar, promover, encorajar, deter, censurar, queimar a produção de textos, originais e traduções. Esses poderes, igrejas, partidos políticos, editoras e editores, programadores de rádio e televisão, projetam a margem e também são capazes de fazêla permanecer, mais ou mesmo completamente em sociedades totalitárias, e menos naquelas não totalitárias. A margem, evidentemente, coincide com a visão de mundo dos patrões e eles são capazes de projetar e reforçá-la porque podem dispensar aos 
escritores, de certo modo, subsistência econômica e certo nicho social, de mais ou menos prestígio, ou sem nenhum deles."

77. Cf. Merkle D., "Towards a Sociology of Censorship: Translation in the LateVictorian Publishing Field", M. WoLF (dir.), Übersetzen - Translating - Traduire: Towards a "Social Turn"?, Wien et Münster, Lit Verlag, 2006, p. 35-44.

78. Merkle D., op. cit., 2010.

79. Hjørnager Pedersen V., "Self-censorship in Victorian Translations of Hans Christian Anderson", T. SERuYa et M. L. Moniz (dir.), Translation and Censorship in Different Times and Landscapes, Newcastle, Cambridge Scholars Publishing, 2008, p. 308-318.

\section{N.T.}

* No original, cabinets de lecture. Refere-se a estabelecimentos públicos que se expandiram no século XIX, onde havia acesso à leitura, por uma pequena taxa, de jornais revistas, livros literários e outros, os quais dificilmente podiam ser comprados em razão do elevado preço. Para mais detalhes, consultar Le Grand Dictionnaire du XIXe siècle. Paris : Larousse, 1865-90. t.3. p.16-17.

** No original, romans à sensations. Trata-se de um gênero literário surgido na Inglaterra vitoriana, cuja temática envolve crimes e adultério no meio burguês (Edwards, P. D. Sensation Novels. Victorian Britain: An Encyclopedia. Ed. Sally Mitchell. London-New York: Garland, 1988. p. 703-704).

*** Os romances em edição de três volumes, ou triple-deckers, estão especificamente relacionados ao período vitoriano e possuem forte vínculo com o sistema de funcionamento das bibliotecas de empréstimo. Para mais detalhes, veja-se, por exemplo: Menke, Richard. "The End of the Three-Volume Novel System, 27 June 1894." BRANCH: Britain, Representation and Nineteenth-Century History. Ed. Dino Franco Felluga. Extension of Romanticism and Victorianism on the Net. Disponível em: http://www.branchcollective.org/?ps_articles=richardmenke-the-end-of-the-three-volume-novel-system-27-june-1894. Acesso em: 07/08/2015. 


\section{Referências}

Anonyme, «Vizetelly and Zola : The Paper Which First Introduced Zola to the English Masses », Star (2 November), 1888, p. 2.

Atkinson J., "'The Most Thrilling and Fascinating Book of the Century': Marketing Gustave Flaubert in Late Nineteenth-Century England », K. Macdonald et C. Singer (dir.), Transitions in Middlebrow Writing, 1880-1930, Houndmills (Basingstoke, Hampshire), Palgrave MacMillan, 2015, p. 163-182.

Baer B., " Literary Translation in the Age of the Decembrists : The Birth of Productive Censorship in Russia », D. Merkle, C. O'Sullivan, L. van Doorslaer et M. Wolf (dir.), The Power of the Pen: Translation and Censorship in Nineteenthcentury Europe, Wien et Münster, Lit Verlag, 2010, p. 213-239.

Bakker B., Correspondance, tome V 1884-1886, Montréal, Presses de l’Université de Montréal et Paris, CNRS, 1985.

Bonnetain P., Rosny J.-H., Descaves L., Marguerite P., Guiches G., Manifeste des Cinq : La Terre, à Émile Zola, sans date. En ligne : http://www.berlol.net/ chrono/des5.htm. Page consultée le 28 juillet 2015.

Bourdieu P., Ce que parler veut dire, Paris, Librairie Arthème Fayard, 1982.

Bourdieu P., Le sens pratique, Paris, Éditions de Minuit, 1980.

Bourdieu P., La distinction. Critique sociale du jugement, coll. «Le sens commun », Paris, Éditions de Minuit, 1979.

Cloarec N. et É. Dardenne, "Censorship v. Freedom of Speech in Englishspeaking Countries. Cultural, Political and Historical Pespectives ", Revue LISA/ LISA-ejournal [En ligne], vol. XI, n ${ }^{\circ}$ 1, 2013, mis en ligne le 30 mai 2013 à https://lisa.revues.org/5171. Page consultée le 28 juillet 2015.

Colligan C., « Obscenity and Empire: England's Obscene Print Culture in the Nineteenth Century » [thèse inédite], Kingston (ON), Queen's University, 2002. 
Coustillas P. (dir. et intro.), Literature at Nurse, or Circulating Morals: A Polemic on Victorian Censorship, Sussex, The Harvester Press Limited, 1976.

Deane S., « Flaubert and the retranslation of Madame Bovary », Flaubert, Revue critique et génétique [En ligne], vol. 6, 2011, mis en ligne le 30 janvier 2012. Page consultée le 28 juillet 2015. URL : http://flaubert.revues.org/1538.

Ellis H., «Introduction » dans Germinal, London, J. M. Dent \& Sons Ltd, 1933, pp. vii-ix.

Ellis H., « Eleanor Marx II », Adelphi, vol. 11, 1 octobre 1935, p. 32-41.

Falconer G., « Madame Bovary and the Translators », P. Bhatt (dir.), Significations: Essays in honour of Henry Schogt, Toronto, Canadian Scholars Press, 1997, 41-50.

Florence R., Marx's Daughters, New York, Dial Press, 1975.

Foucault M., « L'Occident et la vérité du sexe », Le Monde, nº 9885, 5 novembre 1976, p. 24. En ligne : http://1libertaire.free.fr/MFoucault218.html. Page consultée le 28 juillet 2015.

Freshwater H., "Towards a Redefinition of Censorship », B. Müller (dir.), Censorship \& Cultural Regulation in the Modern Age, Amsterdam et New York, Rodopi, 2004, p. 225-245.

Goldstein R. J., "A Land of Relative Freedom: Censorship of the Press and the Arts in the Nineteenth Century (1815-1914) ", P. Hyland et N. Sammells (dir.), Writing and Censorship in Britain, London, Routledge, 1992, p. 125-140.

Hjørnager Pedersen V., "Self-censorship in Victorian Translations of Hans Christian Anderson », T. Seruya et M. L. Moniz (dir.), Translation and Censorship in Different Times and Landscapes, Newcastle, Cambridge Scholars Publishing, 2008, p. 308-318.

James H., « Gustave Flaubert », Madame Bovary, London, Appleton \& Company, 1902, p. v-xliii. 
James H., « Émile Zola » (1903), Veeder et Griffin (dir.), The Art of Criticism: Henry James on the Theory and the Practice of Fiction, Chicago, University of Chicago Press, 1986, p. 423-458.

Kapp Y., Eleanor Marx: Volume II, The Crowded Years (1884-1898), London, Lawrence and Wishart, 1976.

King G., Garden of Zola (Émile Zola and his Novels for English Readers), New York, Barnes \& Noble, 1978.

Lefevere A., "Translations and Other Ways in Which One Literature Refracts Another », Symposium, vol. 38, n 2, 1984, p. 127-142.

Lethbridge R., « Zola and England », Bulletin of the Emile Zola Society, $\mathrm{n}^{\circ} 10$ (April) 1993, pp. 3-13.

Marx-Aveling E., "Introduction ", Madame Bovary, traduction d'E. MarxAveling, London, Vizetelly \& Co, 1886, vii-xxii.

Merkle D., « M. French Sheldon, Translator of Gustave Flaubert's Salammbô: Transauthorship and the Mechanics of Censorship in Late-Victorian Britain », D. Merkle, C. O'Sullivan, L. van Doorslaer et M. Wolf (dir.), The Power of the Pen: Translation and Censorship in Nineteenth-century Europe, Wien et Münster, Lit Verlag, 2010, p. 97-118.

Merkle D., « Secret Literary Societies in Late Victorian England », M. Tymoczko (dir.), Translation, Resistance, Activism, Amherst et Boston, University of Massachussets Press, 2010, p. 108-128.

Merkle D., « Vizetelly \& Company as (ex)Change agent: Towards the Modernization of the British Publishing Industry », J. Milton et P. Bandia (dirs.), Agents of Translation, Amsterdam et Philadelphia, John Benjamins, 2009, p. 85-106.

Merkle D., «Germinal en Grande-Bretagne de 1884 à 1895 : de l'esthétique dominée à l'esthétique dominante ", Cahiers naturalistes, n 81, 2007, pp. 197-210. 
Merkle D., « Towards a Sociology of Censorship: Translation in the Late-Victorian Publishing Field ", M. Wolf (dir.), Übersetzen - Translating - Traduire: Towards a "Social Turn"?, Wien et Münster, Lit Verlag, 2006, p. 35-44.

Merkle D., « The Lutetian Society », TTR, vol. 16, nº 2, 2003, pp. 73-101.

Merkle D., «Émile Zola devant la censure britannique », TTR, vol. 7, n 1, 1994, p. 77-91.

Mullin K., "Pernicious Literature: Vigilance in the Age of Zola (1886-1899) ", D. Bradshaw et R. Potter (dir.), Prudes on the Prowl: Fiction and Obscenity in England, 1850 to the Present, Oxford, Oxford University Press, 2013, pp. 30-51.

Ní Chuilleanáin E., C. Ó Cuilleanáin et D. Parris (dir.), Translation and Censorship. Patterns of communication and interference, Dublin, Four Courts Press, 2009.

(The) National Vigilance Association (NVA), Pernicious Literature. Debate in the House of Commons. Trial and Conviction for Sale of Zola's Novels. With Opinions of the Press, Strand, London, The National Vigilance Association, 1889.

O'Sullivan C., « Margin and the Third-person Effect in Bohn's Extra Volumes », D. Merkle, C. O'Sullivan, L. van Doorslaer et M. Wolf (dir.), The Power of the Pen: Translation and Censorship in Nineteenth-century Europe, Wien et Münster, Lit Verlag, 2010, p. 119-142.

Nelson J. G., Publisher to the Decadents, Pennsylvania Park, The Pennsylvania State University Press, 2000.

Pagès A., La bataille littéraire (Essai sur la réception du naturalisme à l'époque de Germinal), Paris, Séguier, 1989.

Rădulescu A., " Entre censure et autocensure littéraire en Roumanie : L'odyssée d'un journal intime à l'époque communiste », TTR, vol. 23, no 2, 2010, p. 23-52. 
Roberts M. J. D., « Blasphemy, Obscenity and the Courts: Contours of Tolerance in Nineteenth-century England ", P. Hyland et N. Sammells (dir.), Writing and Censorship in Britain, London, Routledge, 1992, p. 141-153.

Robertson G., Q.C., Freedom, the Individual and the Law, London, Penguin, 1989.

Simon S., Gender in Translation, Cultural Identity and the Politics of Transmission, London et New York, Routledge, 1996.

Simon S. (dir.), Numéro thématique : «Traduction engagée/Translation and Social Activism », TTR, vol. 18, $\mathrm{n}^{\circ} 2,2005$.

Speirs D. et Portebois Y., Mon cher Maître, lettres d'Ernest Vizetelly à Émile Zola, Montréal, les Presses de l'Université de Montréal, 2002.

Steiner G., Après Babel: Une poétique du dire et de la traduction, traduction de L. Lotringer, Paris, Albin Michel, 1978.

Thomas D., A Long Time Burning: The History of Literary Censorship in England, London, Routledge et Kegan Paul Ltd., 1969.

Tomaszkiewicz T., " La traduction des textes déjà censurés », TTR, vol. 15, ${ }^{0}$ 2, 2002, p. 171-189.

Tsuzuki C., The Life of Eleanor Marx 1855-1898, London, Oxford University Press, 1967.

Tymoczko M. (dir.), Translation, Resistance, Activism, Amherst, MA, University of Massachusetts Press, 2010.

Tymoczko M. et E. Gentzler (dir.), Translation and Power, Amherst et Boston, University of Massachusetts Press, 2002.

Wolf M., "Censorship as Cultural Blockage: Banned Literature in the Late Habsburg Monarchy », TTR, vol. 15, no 2, 2002, p. 45-62. 
Woods M., Censoring Translation: Censorship, Theatre, and the Politics of Translation, London et New York, Continuum, 2012.

Recebido em: 01/08/2015 Aceito em: 15/09/2015 


\section{Artigo original}

\section{LES ENJEUX DE TRADUIRE FLAUBERT ET ZOLA EN ANGLETERRE VICTORIENNE}

« [...] entre nous, je suis convaincu que les Anglais ont contre mes romans de grandes préventions [...]. Aussi ai-je été beaucoup plus fêté en Angleterre que je ne suis lu ou compris ». Émile Zola, $1893^{1}$.

Le Royaume-Uni est considéré historiquement comme l'une des nations les plus à l'avant-garde en matière des libertés démocratiques, précisément en matière de la liberté d'expression, " traditionnellement présentée comme une valeur fondamentale ${ }^{2} »$. Toutefois, il y a posé des limites quand le bien-être de la nation en avait besoin. Effectivement, le gouvernement britannique et des citoyens ont à des moments différents mis en œuvre des formes d'entrave à la liberté d'expression, et ce jusqu'à la censure, dans « un espace au sein duquel des négociations [ont été] menées entre des individus ou des groupes à propos de pratiques et de discours politiques, sociaux ou culturels ${ }^{3}$ ». Dans A Long Time Burning, Donald Thomas argumente de façon convaincante que les Britanniques n'ont jamais joui d'une liberté d'expression absolue ${ }^{4}$.

L'ère victorienne fournit des cas d'entraves à la liberté d'expression résultant des tensions entre pouvoir, savoir et sexualité que le travail de défricheur de Michel Foucault ${ }^{5}$ aide à comprendre. Les cas servent ici à illustrer comment la culture d'accueil en pleine transformation socio-culturelle, à savoir le Royaume-Uni victorien, reçoit dans l'espace de rencontre qu'est la traduction l'étranger tel que véhiculé dans les écrits de Gustave Flaubert et d'Émile Zola, écrits qui tentent de pénétrer à l'intérieur de son espace socio-cultu- 
ro-politique. Suffit-il de dire que la traduction de leurs œuvres a fait l'objet de controverses pendant cette période. Dans cet article, nous fournirons des exemples de résistance et d'engagement ${ }^{6}$ de la part de quelques traducteurs victoriens des œuvres de Flaubert et de Zola. Commençons d'abord par quelques faits d'histoire pour illustrer le contexte de l'activité traduisante et situer la réception victorienne des œuvres à l'étude.

\section{Quelques faits d'histoire}

Dès 1792, il revient à un jury (la conscience du public) de déterminer la culpabilité d'un accusé. Le jury doit donc, au XIX ${ }^{\mathrm{e}}$ siècle, décider des questions de diffamation criminelle. La loi sur la diffamation criminelle assure le succès des poursuites judiciaires contre toute œuvre jugée obscène parce qu'elle traite de passion sexuelle, par exemple, et à laquelle le grand public (c'est-à-dire les femmes, les enfants, les «nouveaux lecteurs ${ }^{7}$ ») a accès. Toutefois, la tâche de définir l'obscénité relève du tribunal. La Obscene Publications Act de 1857 va plus loin et autorise la police à soumettre les livres destinés au grand public aux juges locaux en vue de les faire confisquer puis détruire pour cause d'obscénité. En 1868, le premier président de la Cour d'appel Cockburn dans la cause de $R$. V. Hicklin laisse une formule affirmant que la preuve de l'obscénité se trouve dans la tendance à dépraver et à corrompre le lecteur ou la lectrice ${ }^{8}$. On croit que les nouveaux lecteurs ont besoin de la protection offerte par une loi ${ }^{9}$ pour les protéger contre la littérature pernicieuse, en guise d'exemples, les œuvres controversées de Flaubert, de Zola et de Maupassant en traduction ${ }^{10}$.

La révolution française de 1789 - avec par surcroît les écrits de Thomas Paine - et celle de 1830 de concert avec l'instruction des classes inférieures provoquent une censure plus sévère au cours du XIX ${ }^{\mathrm{e}}$ siècle. L'alphabétisation de ces classes résulte de l'Education Act de 1870 et des progrès technologiques qui permettent une diffusion plus rapide et plus grande de la littérature destinée au marché de 
masse. L'instruction générale se voit accompagnée de la naissance des ligues de moralité, et des moralistes guidés par le «moralisme petit bourgeois $^{11}$ » se donnent la responsabilité de protéger la classe ouvrière et la classe moyenne des « transgressions symboliques ${ }^{12}$ », qui règnent dans le domaine privé des sociétés littéraires et savantes secrètes. Les moralistes souvent issus de la petite bourgeoisie, souffrent d'une "tension vertuiste ", pour reprendre la formule de Pierre Bourdieu, et d'une "insécurité profonde », ce qui les encouragerait « au phantasme de la 'pornocratie'13 ». Le Parlement compte sur les moralistes pour poursuivre la littérature pernicieuse en justice, et ces derniers ne déçoivent pas.

Dès 1880 , la police et l'instruction obligatoire remplacent les organismes religieux comme garants de la moralité publique. De surcroît, le Parlement et le système judiciaire s'attaquent aux problèmes sociaux que la police et l'instruction obligatoire ne réussissent pas à éliminer ${ }^{14}$. Comme preuve, le compte rendu des débats de la Chambre des communes sur les effets nocifs de la littérature pernicieuse sur la nation britannique du 8 mai 1888 rapporte que le député du Leicestershire se prononce en faveur de la censure de la littérature pernicieuse, dont bon nombre de traductions, car il croit qu'elle risque de fomenter les sentiments révolutionnaires auprès de la population vulnérable - les nouveaux lecteurs - grouillements qui commencent déjà à se faire entendre ${ }^{15}$. Il est permis d'affirmer que le Parlement veut protéger la stabilité morale et politique, ainsi que l'intégrité de la nation, et n'hésite pas à faire appel à la censure.

La vigilance du Parlement pendant les années 1880 s'explique de la façon suivante. À partir de 1865 , la société victorienne se démocratise davantage ; par conséquent, la classe dominante est sur la défensive. Le taux d'analphabétisation passe de 30 pour cent en 1861 à 5 pour cent en 1892 , et les éditeurs novateurs tels que Henry Vizetelly qui s'affranchit du système des cabinets de lecture, ou des bibliothèques de prêt [circulating librairies à la Mudie's Circulating, ou Select, Library], publient des romans à sensation en traduction en un seul volume et à bon marché. Les nouveaux lecteurs peuvent désormais se payer des livres. Le 16 décembre 1884, 
James Davis écrit que du fait que les écrivains n'ont qu'à mettre sur le marché à un prix abordable les livres que réclame le public, ils n'auront plus besoin de bibliothèques de prêt ${ }^{16}$, institution qui écarte tout titre dont la teneur morale est suspecte. Si les écrivains veulent que ces bibliothèques incluent leurs ouvrages dans les listes de livres à prêter, ils se voient obligés de se plier aux contraintes imposées par les bibliothèques, alors que les éditeurs novateurs, tel Vizetelly, les en libèrent. Cette révolution du monde de l'édition provoque une réaction auprès des députés, responsables d'assurer l'ordre social, et des moralistes ${ }^{17}$. Toutefois, le Parlement préfère que les particuliers, dont les moralistes, poursuivent les auteurs, dont l'œuvre est jugée obscène, ou bien l'éditeur quand il s'agit d'une traduction.

Si on remonte au XVIII ${ }^{\mathrm{e}}$ siècle, on note que David Hume critique en 1777 la « unbounded liberty of the press ${ }^{18}$ » en Grande-Bretagne. Hume exprime ici la crainte de la foule, de la révolution et du républicanisme qu'il partage avec bon nombre de ses compatriotes " porte-paroles autorisés ${ }^{19}$ ». Un siècle plus tard, la réception victorienne de produits littéraires français, à titre d'exemple, qui revendiquent la réforme sociale, l'anticléricalisme ou le républicanisme demeure foncièrement problématique. Le député Samuel Smith insiste sur la responsabilité des classes supérieures de se comporter en modèle à imiter jusqu'à dans leurs lectures. Néanmoins, il faut se rappeler que la littérature obscène, précisément la pornographie ${ }^{20}$, a toujours été à la disposition des membres des classes supérieures, un exemple par excellence du "third-person effect ${ }^{21}$ ». Ce qui vexe tant ces classes vers la fin du XIX ${ }^{\mathrm{e}}$ siècle est que, soudain, les classes inférieures qui auparavant n'y avaient pas accès peuvent dorénavant se la procurer ouvertement et à bas prix. Afin de maintenir l'ordre traditionnel et d'assurer la place privilégiée de l'élite, tout comportement qui ne demeure pas dans les limites de la bienséance doit rester dans le domaine privé22. En conformité avec la pensée de Foucault, les institutions variées - les bibliothèques de prêt, le système juridique, le Parlement, les ligues de moralité - ne peuvent empêcher la diffusion de la 
littérature érotique, qui est florissante à cette époque ${ }^{23}$, quoique clandestine. Voilà un champ d'édition à deux vitesses : l'édition publique (bibliothèques de prêt) et l'édition privée (sociétés littéraires secrètes). Regardons de plus près la réaction du champ d'édition à un entrepreneur tel que Henry Vizetelly, qui a tenté de s'y tailler une place.

\section{Vizetelly \& Company, et les romans scandaleux de Zola et de Flaubert}

a. Zola

Dans son livre Garden of Zola (1978), Graham King prévient le lecteur anglophone de la piètre qualité des traductions en anglais des romans de Zola ; en fait, il consacre un chapitre entier à l'étude des valeurs victoriennes, à l'influence de ces valeurs sur la création littéraire et sur la traduction, mettant l'accent sur l'influence de Thomas Bowdler. Dans la préface à The Family Shakespeare, Bowdler écrit qu'il a supprimé "everything that would raise a blush on the cheeks of modesty ${ }^{24}$ ». Il meurt en 1825, et ses disciples, dont Charles Edward Mudie et W. H. Smith, continuent son travail. En 1842, Mudie ouvre la Select Library, la plus importante bibliothèque de prêt ou «circulating library » qui a le monopole de la production littéraire anglaise entre 1850 et 1890. Mudie et son homologue Smith sélectionnent tous les manuscrits qui feront partie de leur collection respective et exigent des éditions de trois volumes ("triple-deckers») et à faible tirage afin de rendre les prix prohibitifs.

Éditeur des traductions anglaises de Zola et de Flaubert, parmi d'autres écrivains français, et fondateur-propriétaire de la maison Vizetelly, Henry Vizetelly a joué un rôle important dans la bataille contre les traductions en trois volumes prêtées par les circulating libraries, seul diffuseur respectable de livres, pendant les années 1880. Le contexte dans lequel il veut entreprendre 
ces traductions est ainsi une société hostile à tout ce qui n'est pas bienséant, où l'on vit toujours dans l'ombre de Bowdler et où la ligue de moralité (National Vigilance Association), fondée en 1886 afin de promouvoir la pureté sociale, jouit d'un certain pouvoir politique. Ce pionnier de l'édition moderne revient dans cette société oppressive après avoir passé une vingtaine d'années à Paris (entre 1860 et 1880), où il était journaliste. C'est à Paris qu'il fait la connaissance de Zola en 1870, et, en 1877, qu'il est témoin du scandale causé par l'Assommoir (roman et pièce) entre autres ouvrages du maître de Médan. Vizetelly se rend vite compte que le succès de cet écrivain est « fondé sur le scandale $»^{25}$. Et il espère que ses traductions rapporteront autant que les œuvres originales ${ }^{26}$. Vizetelly \& Co entame la traduction des romans de Zola avant celle des romans de Flaubert.

Le premier roman de Zola qui ait paru en Grande-Bretagne, en 1883, dans une traduction anglaise de Frank Belmond, était The Ladies' Paradise [Au bonheur des dames]. Les bibliothèques de prêt avaient refusé de stocker ce livre en trois volumes, publié par la maison Tinsely Brothers, le trouvant condamnable sur le plan moral. Tinsley Brothers, pourtant l'un des «porte-paroles autorisés $^{27} \gg$ du discours légitime des classes moyennes, s'est mépris sur la réception de cette traduction. Certes, ce triple-decker avait été expurgé, mais il était encore loin de reproduire le «moralisme petit bourgeois $^{28} »$. Par conséquent, la traduction n'a pas trouvé preneur parmi les bibliothèques de prêt ${ }^{29}$. En fin de compte, c'est Vizetelly \& Co qui la publie en 1886 .

À son retour à Londres en 1880 et convaincu de l'existence d'un marché de masse pour les œuvres de Zola en traduction, Henry Vizetelly a su saisir l'occasion, tout en sachant que les ligues de moralité ne voulaient assurément pas que les « nouveaux lecteurs " des classes ouvrières aient accès aux éditions bon marché. Néanmoins, les romans en version originale circulaient librement, afin d'assurer que seuls les gens instruits issus généralement des classes privilégiées avaient libre accès aux romans étrangers, dont ceux de Zola et de Flaubert. Pour sa part, Vizetelly espérait que les traduc- 
tions suscitent l'intérêt auprès des nouveaux lecteurs et augmentent ses recettes. Sa maison d'édition a publié des romans de Zola en traduction, en l'occurrence Nana en mars 1884, The 'Assommoir' [L'Assommoir] en juillet 1884, Piping Hot! [Pot-Bouille] en février 1885 et Germinal en juillet 1885, entre autres titres. Ces traductions, en principe du moins non abrégées, étaient scandaleuses, et elles se vendaient aux kiosques de livres. Quant aux cercles littéraires établis, ils les ont honnies. À cause du grand succès de ces romans en France, Vizetelly a acheté les droits d'auteur anglais de toutes les œuvres de Zola. Toutefois, les traductions étaient des versions expurgées de l'original, car elles étaient destinées aux nouveaux lecteurs chez qui régnait une « esthétique dominée ${ }^{30}$ ». Le lecteur britannique qui lisait ces œuvres en traduction ne connaissait donc qu'un Zola habillé à l'anglaise.

C'est Albert Vandam qui a produit la première traduction expurgée de Germinal $^{31}$. Le journaliste-traducteur avait tenu compte du goût du public britannique et a pratiqué l'autocensure. La traduction a paru en feuilleton dans The People du 30 novembre 1884 au 26 avril 1885 sous le titre Germinal, or Master and Man ${ }^{32}$. Selon plusieurs critiques, Vandam ne réussit tout simplement pas à reproduire l'intensité de l'œuvre originale : "Sont atténués ou supprimés dans la version anglaise du roman les scènes de vie familiale trop intimes, [la promiscuité,] la violence, certains propos anticléricaux et des réflexions révolutionnaires ${ }^{33} »$. L'exclusion de "la représentation de certains réalités ${ }^{34}$ " nous place devant une traduction qui subordonne l'art de Zola à la « disposition éthique ${ }^{35}$ » bourgeoise, sinon petite bourgeoise.

Henry Vizetelly a acheté les droits de reproduction et publié sous forme de livre une version plus complète de Germinal que celle qui a paru dans The People. La publicité publiée dans le catalogue de Vizetelly \& Co d'avril 1885 précise que la traduction de Germinal de même que celles de La Curée [The Rush for the Spoil] et de Thérèse Raquin étaient en préparation. Le nom de Zola apparaît assez fréquemment dans les annonces publicitaires de la maison Vizetelly, de même que dans les pages de The Bookseller. 
Au mois de juillet paraît la première édition anglaise non illustrée de Germinal, or Master and Man : A Realistic Novel. Le volume portait une couverture illustrée, montrant Maheu qui écarte sa chemise, découvrant sa poitrine devant les baïonnettes des soldats qui protègent la mine. À l'encontre des autres traductions publiées pour la maison Vizetelly, la parution de l'édition non illustrée, plus modeste, a précédé la parution de l'édition illustrée.

Lors de sa parution en 1887, la Terre a provoqué une critique dans l'ensemble très négative en France. Les "Cinq » dans leur Manifeste devenu fameux écrivent : " la note ordurière du roman était exacerbée encore, descendue à des saletés si basses que, par instants, on se croirait devant un recueil de scatologie ${ }^{36}$ ». Malgré le scandale français, ou peut-être à cause de celui-ci, Vizetelly fait faire la traduction anglaise de ce roman. Vers la fin 1887 , le premier traducteur a refusé de terminer la traduction de la Terre à cause du langage, et un deuxième a réagi de la même façon. C'est pourquoi Ernest Vizetelly, le fils de Henry, a recommandé la suppression de certains passages et la modification du vocabulaire. En mars 1888, The Soil était prêt pour l'impression. Entre temps, la ligue de moralité avait demandé l'appui du moraliste William Stead, éditeur du Pall Mall Gazette, dans sa campagne de censure des traductions publiées par Vizetelly \& Co. Dans un article, Stead écrit que Vizetelly n'avait aucunement essayé d'expurger les romans de Zola, à quoi Vizetelly répond qu'aucune de ses traductions n'est une reproduction fidèle.

\section{b. Flaubert et Madame Bovary ${ }^{37}$}

Eleanor Marx fait ses premières traductions de textes politiques sous la direction de son père, Karl Marx. Au moment de traduire Madame Bovary, elle termine sa traduction de L'Histoire de la commune de Lissagaray, et assiste dans la traduction de Capital ${ }^{38}$. Une motivation politique et morale, ainsi que pécuniaire (la traduction figure parmi ses métiers), l'a poussée à traduire Madame Bovary.

Eleanor MarX-Aveling ${ }^{39}$ n'est pas d'abord connue comme un 
personnage littéraire, mais, en réalité, elle a beaucoup travaillé dans les lettres (au sens large) ayant fait bon nombre de traductions à partir du français (Madame Bovary et essais politiques), du norvégien (pièces d'Ibsen) et aussi de l'allemand (textes politiques) ${ }^{40}$. Sa traduction de Madame Bovary est faite à partir de l'édition définitive de 1873 qui comprend le roman non expurgé, le réquisitoire, la plaidoirie et le jugement. Marx-Aveling y travaille à partir de novembre 1885 et pendant le premier trimestre de 1886 ; la traduction paraît au mois d'août 1886. Cette date coïncide d'assez près avec la parution de «The Woman Question », essai qui dénonce la situation des femmes dans les sociétés capitalistes. À l'encontre de Zola qui échange des lettres avec les Vizetelly, Flaubert étant décédé, la traductrice ne pouvait lui écrire pour lui demander sa collaboration. Depuis le procès de 1857 , date à laquelle le procureur impérial a tenté de vilipender le roman, Madame Bovary connaît un succès grandissant, et il aboutit bientôt au statut de chef d'œuvre en France en reconnaissance de son originalité et de sa virtuosité artistiques. En Angleterre, cependant, Flaubert est affligé de la même mauvaise réputation que celle attribuée à Maupassant et à Zola. Même Henry James qui se montre par moments généreux dans ses éloges de Zola se montre plus circonspect lorsqu'il s'agit de Madame Bovary ou de l'Éducation sentimentale de Flaubert ${ }^{41}$. Heureusement, Flaubert a également ses défenseurs, dont Havelock Ellis qui allait commander, par l'intermédiaire de George Moore, la traduction de Madame Bovary pour le compte de Vizetelly \& Co.

La traductrice a eu une relation d'amitié, grâce à leur intérêt mutuel pour le théâtre, avec George Moore, dont elle estimait les romans audacieux ${ }^{42}$. Elle écrit à sa sœur, Laura Lafargue, que c'est grâce à Moore qu'elle a obtenu le contrat bien rémunéré de la traduction de Madame Bovary ${ }^{43}$. Le 23 avril 1886, Marx-Aveling termine sa traduction, et elle écrit à nouveau à Laura : "I have (the Lord be praised!) finished my translation... It has been work! It will be out ere very long I suppose [...], and I am now working at an 'Introduction' to it $»^{44}$. Bien qu'imparfaite selon certains, y compris la traductrice, cette traduction est restée pendant long- 
temps la seule version anglaise disponible ${ }^{45}$.

C'est la première traduction du chef d'œuvre de Flaubert à paraître en Angleterre, comme toutes les traductions d'Eleanor Marx-Aveling ${ }^{46}$. Cependant, dans une lettre écrite en 1862 Flaubert fait référence à une traduction britannique «[f]aite sous mes yeux », et, selon lui, « un chef d'œuvre ${ }^{47}$ ». Toutefois, Flaubert n'a pas réussi à identifier une maison d'édition qui accepte de publier la traduction; la notoriété négative du procès public et tristement célèbre de 1857 mené par le procureur impérial qui accusait le roman, et son auteur, d'outrage contre la moralité publique et la religion a sans doute découragé les éditeurs victoriens bienséants.

Or, pour Marx-Aveling c'était un contrat original, intéressant sur le plan intellectuel et politique. Il n'est donc certainement pas par pur intérêt pécuniaire qu'elle ait accepté le contrat. D'abord, rappelons que c'est une femme aux intérêts littéraires marqués, qui décide de traduire un chef d'œuvre littéraire, dont l'originalité et le mérite étaient reconnus en France dès cette époque. Cependant, son intérêt ne s'arrête pas là. De toute évidence, la fille de Karl Marx a vu dans Emma un exemple poignant de l'inégalité dans laquelle la société tenait les femmes, et a accepté le travail afin de contester les normes de moralité de son époque ${ }^{48}$.

Eleanor écrit dans son introduction à la traduction en date de mai 1886 que, du fait que Flaubert était encore si peu connu en Angleterre, une introduction s'avérait nécessaire à cette première traduction $^{49}$. Elle continue que c'était l'honneur éternel de Flaubert que le roman ait été poursuivi en justice par le gouvernement de Napoléon III. Monsieur le procureur, a-t-elle écrit, trouve plus de faute dans la conception de l'adultère que dans la description minutieuse d'une maladie morale, à savoir la concupiscence (dont souffrait également le conjoint d'Eleanor, Edward Aveling). Les autorités françaises ont cru que Flaubert - tout comme Zola d'ailleurs - n'intervenait pas assez souvent dans son récit afin de condamner le comportement d'Emma et celui d'autres personnages. $\mathrm{Au}$ contraire, il s'est contenté d'observer et de constater. Eleanor 
réagit dans son introduction en précisant que "the fig-leaf morality of the avocat revolts ${ }^{50}$ ", c'est-à-dire l'hypocrisie des tribunaux. Selon sa traductrice, Flaubert fournit un miroir de cette société bourgeoise déchue, et c'est bien ceci, plutôt que l'intrigue d'adultère du roman, qui avait tant scandalisé la société française et qui allait tant scandaliser trente ans plus tard la société anglaise. Eleanor croit tout simplement naturel que ceux qui y reconnaissent leur propre image soient choqués ${ }^{51}$. Sur le plan personnel, Eleanor était fascinée par le personnage d'Emma, femme bourgeoise qui se faisait des illusions et qui n'était pas fidèle à elle-même. La vie d'Emma n'avait pas d'utilité ni de but ; elle n'avait rien à faire ${ }^{52}$.

Et que dire de la traduction? Les traces de «bowdlerism» y sont minimes (la traductrice écrit, p. ex., « confinement ») ; il n’y a pas de coupures. Marx-Aveling écrit dans son "Introduction ", "but at least...I have neither suppressed nor added a line, a word... ${ }^{53} »$. Il est évident qu'elle ne respectait pas la convention sociale de l'époque et mettait de côté les énoncés du $\mathrm{D}^{\mathrm{r}}$ Bowdler lorsqu'elle traduisait le roman. La traductrice affirme que sa traduction est intégrale, voire littérale, et non expurgée. Nous ignorons si elle y faisait une allusion oblique à l'expurgation faite sur les traductions de Zola à ce moment par la maison Vizetelly, la même maison que celle qui a publié sa traduction.

Or, au moins un critique littéraire a commenté le manque de discrétion dans sa traduction. Par exemple, un article qui a paru dans The Athenaeum précise que la traduction comprend : "not in itself a beautiful sentence " et qu'elle a été faite "with more zeal than discretion ${ }^{54} »$. L'auteur de l'article remet en question la parole non-censurée de Marx-Aveling et le fait que la traductrice ne dénonce pas dans son introduction le comportement d'Emma, personnage dont le comportement a choqué le lecteur moyen des années quatre-vingts et que le lecteur bien-pensant trouvait condamnable. Au contraire, Marx-Aveling montre de la compassion pour Emma. Il ne doit donc pas étonner que la traduction, tout comme l'original, rencontre l'opposition pour outrage à la moralité dans la presse 
et de la part de la ligue de moralité. Les défenseurs victoriens de la moralité publique considèrent comme pornographiques Madame Bovary et Salammbô, mais ne poursuivent pas la dernière traduction. La National Vigilance Association s'est contentée de cibler Madame Bovary en $1888^{55}$.

L'éditeur de la collection « The Mermaid Series » dans laquelle a paru Madame Bovary, Havelock Ellis, dans l'article sur la vie d'Eleanor Marx qui a paru dans Adelphi, ne vante pas le mérite de la traduction :

«I asked Eleanor to translate An Enemy of Society. [...] she had already done literary work, notably her translation of Flaubert's Madame Bovary, not indeed a faultless piece of work, but for many years the only version of that masterpiece available for English readers ${ }^{56}$. »

Par contre, William Sharp, spécialiste de la poésie britannique, française et germanique de l'époque, considère cette traduction non seulement comme " fidèle », mais aussi comme " naturelle ${ }^{57}$ » et, l'original comme intraduisible. Sur ce dernier point, il est d'accord avec la traductrice, qui le considère comme "inimitable ». Toutefois, il remarque que Flaubert n'a aucun intérêt pour ceux qui ne savent pas lire le français, confirmant ainsi la convention que seuls les gens instruits devaient et savaient lire de tels romans. Il est intéressant de noter que George Steiner sent l'influence de l'ère victorienne dans la traduction, quoiqu'il ne semble pas partager l'avis de Sharp quant à son «naturel ». Il écrit à ce sujet : «Lue de nos jours, cette version qui manque souvent de finesse retombe sur ses pieds grâce à un parfum d'époque ${ }^{58}$ ", bien qu'il ne fournisse aucune preuve textuelle pour étayer son assertion ${ }^{59}$. 


\section{Henry Vizetelly devant les tribunaux}

Henry Vizetelly a dû comparaître deux fois devant les tribunaux ${ }^{60}$. Le 31 octobre 1888, âgé de 68 ans et en mauvaise santé, il se trouvait à la Old Bailey à Londres, pour défendre sa traduction de Nana, de Pot Bouille et de la Terre. Le procureur, Sir Edward Clarke, a lu quelques passages de The Soil, qui traitaient de l'accouplement d'un bœuf et d'une vache, de viol, de meurtre, d'inceste, ainsi de suite. Au neuvième passage, le jury a refusé d'en entendre davantage. Vizetelly a fini par plaider coupable. Il a dû payer une amande de 100 livres sterling et a été condamné avec sursis à une peine de douze mois d'emprisonnement. La réaction des journaux était vive et témoignait du parti-pris contre Vizetelly. Après le premier procès, Vizetelly \& Co annonce en janvier 1889 que Germinal, or Master and Man fera partie de la liste des traductions qui seront réimprimées avec des illustrations originales, après révision, et vendues à moindre prix. Cette révision correspond en réalité à l'obligation d'une seconde expurgation opérée par Ernest Vizetelly. Du fait que la maison Vizetelly frôlait la faillite à la suite du premier procès, baisser le prix devait assurer la vente en grand nombre de ces traductions qui rempliraient les coffres vidés par le procès. L'éditeur a continué ainsi à vendre les livres qui, d'après lui, n'avaient pas été cités dans le jugement (en fait, le jugement était très vague).

Le 30 mai 1889, à la cour criminelle centrale de Londres, a eu lieu un second procès de Henry Vizetelly. La ligue de moralité a mis, de nouveau, à la liste de livres à interdire Madame Bova$r y$, mais le juge a refusé de poursuivre ce roman, car il craignait de perdre la cause du fait que ce livre commençait à se faire reconnaître comme un chef d'œuvre non seulement en France, mais aussi en Angleterre par l'élite intellectuelle. L'accusation portait alors sur The Rush for the Spoil, The Fortune of the Rougons, Fat and Thin (Le Ventre de Paris), The Assommoir, Abbe Mouret's Transgression, His Excellency Eugene Rougon, How Jolly Life Is (La Joie de vivre) et Bel Ami (de Maupassant). Il est intéressant de 
constater que la traduction d'une œuvre de Zola qui se verra retirer de la deuxième liste de traductions visées - celle de Germinal est celle qui avait d'abord paru dans The People, porte-parole de l'Église et de l'État, en d'autres mots porte-parole du discours autorisé. Il semble que ce soit l'appui conjoint du People et du Globe qui ait protégé cette traduction. Les autres traductions incriminées lors du premier procès (Nana, Piping Hot ! et The Soil) étaient naturellement interdites. Vizetelly a plaidé coupable à la recommandation de son avocat. Le procès fut très bref. Comme l'éditeur n'était pas en mesure de payer une amende, il a été condamné à trois mois de prison pour récidive. Cette fois-ci les journaux se sont tus. Peu après, Vizetelly \& Co a fait faillite.

Tout le monde n'était pas en faveur du jugement contre Vizetelly \& Co. En fait, le 2 novembre 1888 paraissent dans The Star deux articles ${ }^{61}$ qui traitent du premier procès contre Vizetelly et qui dénoncent le jugement. Dans le premier intitulé «Vizetelly and Zola : The Paper Which First Introduced Zola to the English Masses ", l'éditeur répond à une question qui porte sur le jugement. Il explique qu'il ne sait pas exactement quels titres ont été interdits, du fait de rapports contradictoires. En réalité le tribunal a surtout poursuivi La Terre mais le jugement a porté sur plusieurs titres. Vizetelly ajoute qu'il n'a pas réussi à trouver un bon avocat pour défendre sa cause du fait que plusieurs avocats étaient également députés au Parlement et que ces derniers craignaient d'offusquer les membres de leurs circonscriptions respectives.

Le deuxième article est une lettre ouverte signée « un romancier » [a novelist $]$ et intitulée : "The Vizetelly Prosecution : To the Editor of 'The Star' ». C'est un plaidoyer en faveur de la liberté d'expression et de la liberté de la presse. L'auteur voudrait que les hommes de loi aient conscience de leurs devoirs et de leurs responsabilités en tant que citoyens d'un pays démocratique. Enfin, l'auteur suggère que la véritable question que pose Zola est la suivante : un écrivain moderne a-t-il le droit d'exposer les maux de sa société ? Pour sa part, Vizetelly précise qu'il avait fait son possible pour transformer les romans de Zola en « représentation 
légitime ${ }^{62}$. Il explique ainsi au journaliste du Star qu'il avait tenté d' " habiller la Terre à l'anglaise ${ }^{63}$. Paradoxalement, cet effort était vain et non reconnu au cours du premier procès.

Visant toujours un marché de masse, Ernest Vizetelly vend vers 1895 les droits de la traduction anglaise de Germinal, entre autres titres de Zola, à la maison Chatto \& Windus, qui publiera en 1901 une traduction plus expurgée encore que celle qui résulte de la deuxième expurgation de 1888. C'est Ernest Vizetelly lui-même qui fera la nouvelle version. À ce sujet, il écrit une lettre à Zola le 7 janvier 1895 :

\begin{abstract}
"Il est certain que j'ai (de concert avec vous) des droits sur La Terre et Germinal, et par conséquent mes demandes [Ernest Vizetelly revendique des droits à la Lutetian Society] sont bien fondées. Une fois cette affaire réglée, je vais tâcher de lancer une édition bon marché de Germinal, après avoir adouci ou supprimé, quelques passages qui pourraient créer des ennuis. De sorte que nous retirerons deux fois de l'argent de ce livre ${ }^{64}$.»
\end{abstract}

Effectivement, en 1894, Chatto \& Windus s'est porté acquéreur des droits anglais de Zola et Ernest Vizetelly, qui y travaillait, poursuivait l'expurgation et l'altération de quinze traductions pour ne pas offenser le public (sauf, bien entendu, la Terre, Nana et Pot-Bouille qui étaient toujours interdits en Angleterre). Ernest Vizetelly inclut Germinal dans la liste des traductions anglaises et américaines qui «sont à l'index ici $^{65}$ » dans une lettre qu'il écrit à Zola le 7 août 1893. Il est intéressant de noter le nombre d'exemplaires de traductions vendues en Grande-Bretagne jusqu'en 1911 : Nana 2150000 (contre 198000 en France), Piping Hot ! 102000 (95 000), Germinal 132000 (110 000), The Soil 162000 $(135000)^{66}$. Le nombre d'exemplaires de traductions victoriennes souvent des traductions interdites - dépassent largement le nombre d'exemplaires vendu en France. 


\section{Quelques mots sur la Société Lutétienne [The Lutetian Society $\left.^{67}\right]$}

$\mathrm{Si}$, dans le domaine public du champ de la littérature traduite, une langue expurgée était la norme discursive, il n'y avait pas de telles contraintes dans le domaine privé des sociétés littéraires et savantes secrètes où la « transgression symbolique ${ }^{68}$ » régnait. Au moment où Henry Vizetelly se faisait poursuivre en justice pour avoir publié des traductions jugées obscènes, Richard F. Burton faisait publier sous la protection de la société littéraire secrète mais inventée, la Kamashastra Society of London and Benares, 1000 exemplaires de sa traduction non expurgée et érotisée, des Mille et une nuits [A Thousand Nights and a Night] vendue par souscription. En outre, le système socio-culturel tolérait la libre diffusion de livres écrits en langue étrangère, car seules les personnes éduquées (celles qui détiennent le pouvoir politique) y ont accès. Par ailleurs, les autorités surveillaient de beaucoup moins près les prétendus classiques de la littérature européenne même en traduction, situation qu'exploite à succès Henry Bohn dans ses volumes « supplémentaires » [extra volumes] ${ }^{69}$. Zola a aussi eu droit à l'intérêt d'une société littéraire secrète.

Pendant la deuxième semaine de juillet 1894 ont paru dans les journaux de Londres des entrefilets annonçant la publication autorisée par Zola, de douze volumes des Rougon-Macquart par la Lutetian Society, une société savante et secrète ${ }^{70}$. La maison new-yorkaise Henry Holt \& Company, éditrice de la Lutetian Society, aurait demandé le 5 février 1894 à Zola « l'autorisation de publier une édition à petit nombre de ceux de ses ouvrages qui étaient tombés dans le domaine public - édition qui devait être lancée par souscription, chaque volume étant coté à un prix relativement élevé ${ }^{71} »$. Le tirage de ces volumes s'est limité à 310 exemplaires. Ernest Vizetelly a rassemblé les prospectus de cette société envoyés depuis Londres, Irlande, Écosse... Il semble ne pas avoir existé de correspondance entre Zola et la Lutetian Society, le romancier n'ayant, pour les traductions en anglais, à 
part avec les Vizetelly, traité qu'avec la maison Henry Holt \& Company. Une lettre de cet éditeur à destination de Zola en date du 8 mars le remercie de son autorisation de publier une nouvelle traduction de ses romans ${ }^{72}$. Le lien entre l'éditeur américain et la Lutetian Society reste néanmoins obscur.

C'est Alexander Teixeira de Mattos qui a dirigé à Londres entre 1894 et 1895 la retraduction de six romans de Zola. Collaboraient également au projet : Arthur Symons (L'Assommoir), Ernest Dowson (La Terre), Victor Plarr (Nana) et Percy Pinkerton (Pot-Bouille). Teixeira de Mattos s'est occupé de la traduction de la Curée et s'est adressé à Havelock Ellis pour la traduction de Germinal. Ce dernier a accepté car, comme il le précise dans son introduction, il avait besoin d'argent. Ellis avait travaillé dans l'édition dans les années 1880, notamment à titre de directeur de la Mermaid Series de Vizetelly \& Co, mais il n'avait jamais encore fait de traduction. L'écrivain a signé le contrat le 15 février 1894, les cosignataires étant Joseph Hannaford Bennet et Leonard Smithers, deux éditeurs de Londres. Smithers, disciple et collaborateur de Burton, allait guider les activités de la Lutetian Society ${ }^{73}$.

Havelock Ellis a aimé faire cette traduction et a développé à cette occasion plus d'estime pour le maître de Médan. Dans l'introduction à sa traduction, il raconte avoir traduit à voix haute et que c'est sa femme qui écrivait. Cette façon de faire lui a fait découvrir tous les arcanes de l'œuvre de Zola et lui a permis de s'interroger sur la structure du roman, ce que - d'après lui - la simple lecture ne permet pas. Tout en reconnaissant les défauts de son travail, le (re)traducteur de Germinal se montre convaincu de l'importance du roman et se réjouit d'avoir produit la seule traduction anglaise non expurgée, de cette $"$ grande fresque $»^{74}$. Mais il ne fera pas d'autres traductions. De fait, toutes les six traductions produites par la Lutetian Society étaient non expurgées. 


\section{En guise de conclusion}

À la suite de l'adoption de la Lord Campbell's Obscene Publications Act en 1857, une série de procès - ceux de Hicklin (1868), de Bradlaugh et Besant (1877) et de Vizetelly (1888 et 1889) - fait état de la « marge $[\text { margin }]^{75}$ » réduite des éditeurs qui travaillent dans le domaine public et fournissent des précédents dont l'influence allait se faire sentir jusqu'à la deuxième moitié du $\mathrm{xx}^{\mathrm{e}}$ siècle.

La genèse de la traduction des œuvres de Flaubert, mais surtout celles de Zola, en Angleterre entre 1884 et 1895 s'inscrit dans un champ de tensions entre le domaine public, où régnait un conformisme éthique soutenu par les moralistes bourgeois et petits-bourgeois bien-pensants, et le domaine privé où des « libertins » des classes supérieures cherchaient à faire valoir l'altérité morale et l'art pour l'art. En effet, un système d'édition à deux vitesses est une manifestation de la censure structurale qui reproduit globalement la structure sociale (les privilégiés et les autres) ${ }^{76}$. Les œuvres conformistes sont publiées dans la sphère publique, alors que les œuvres controversées (p. ex., les traductions non expurgées des romans interdits de Zola) sont publiées en privé.

Les éditeurs œuvrant dans le domaine public peuvent être accusés d'obscénité, alors que les éditeurs œuvrant dans le domaine privé (sociétés secrètes qui vendent leurs œuvres aux «membres » et aux abonnés) sont à l'abri de la loi. Grâce aux normes respectées et aux tabous non transgressés au XIX ${ }^{\mathrm{e}}$ siècle - du moins par la majorité de la population britannique -, l'autocensure prend souvent la relève de la censure dans la traduction de textes qui visent le grand public, comme par exemple The Ladies Paradise produite pour Tinsley Brothers et la traduction de Germinal produite pour The People. Les œuvres expurgées ayant une vocation didactique, destinées aux femmes et aux enfants (p. ex., la traduction des Mille et une nuits produite par Isabelle Burton ${ }^{77}$, les contes de Hans Christian Anderson ${ }^{78}$ ) et aux classes ouvrières (les traductions de Flaubert et Zola publiées par la maison Vizetelly), sont assainies afin de fournir des modèles d'expression autorisés. 
Toutefois, même habillées à l'anglaise, Nana, Piping Hot et The Soil n'étaient pas à l'abri de la censure. Si on n'a pas osé interdire la traduction de Madame Bovary, il faudra attendre jusqu'aux années 1950 avant que le Royaume-Uni ne lève l'interdiction de vente de ces trois romans de Zola en traduction.

\section{Notes}

1. Dans Lethbridge R., «Zola and England », Bulletin of the Emile Zola Society, no 10 (April) 1993, pp. 3-13, p. 5.

2. Cloarec N. et É. Dardenne, «Censorship v. Freedom of Speech in Englishspeaking Countries. Cultural, Political and Historical Pespectives », Revue LISA/ LISA-ejournal [En ligne], vol. XI, n ${ }^{\circ}$ 1, 2013, mis en ligne le 30 mai 2013 à https://lisa.revues.org/5171. Page consultée le 28 juillet 2015.

\section{Ibid.}

4. Thomas D., A Long Time Burning: The History of Literary Censorship in England, London, Routledge et Kegan Paul Ltd., 1969.

5. Voir, à titre d'exemple, Foucault M., "L'Occident et la vérité du sexe », $L e$ Monde, $\mathrm{n}^{\circ}$ 9885, 5 novembre 1976, p. 24 [En ligne], http://1libertaire.free.fr/ MFoucault218.html. Page consultée le 28 juillet 2015.

" On touche là à un problème plus général qu'il faudra bien traiter en contrepoint de cette histoire de la sexualité, le problème du pouvoir. D'une façon spontanée, quand on parle du pouvoir, on le conçoit comme loi, comme interdit, comme prohibition et répression ; et on est bien désarmé quand il s'agit de le suivre dans ses mécanismes et ses effets positifs. Un certain modèle juridique pèse sur les analyses du pouvoir, donnant un privilège absolu à 
la forme de la loi. Il faudrait écrire une histoire de la sexualité qui ne serait pas ordonnée à l'idée d'un pouvoir-répression, d'un pouvoir-censure, mais à l'idée d'un pouvoir-incitation, d'un pouvoir-savoir ; il faudrait essayer de dégager le régime de coercition, de plaisir et de discours qui est non pas inhibiteur, mais constitutif de ce domaine complexe qu'est la sexualité. »

6. Voir, par exemple, Simon S. (dir.), Numéro thématique : "Traduction engagée/Translation and Social Activism ", TTR, vol. 18, n 2, 2005, Tymoczko M. (dir.), Translation, Resistance, Activism, Amherst, MA, University of Massachusetts Press, 2010, et Tymoczko M. et E. Gentzler (dir.), Translation and Power, Amherst et Boston, University of Massachusetts Press, 2002.

7. Ces nouveaux lecteurs proviennent des classes ouvrières.

8. Voir Robertson G., Q.C., Freedom, the Individual and the Law, London, Penguin, 1989, p. 180, qui cite Cockburn : "I think the test of obscenity is this, whether the tendency of the matter charged as obscenity is to deprave and corrupt those whose minds are open to such immoral influences, and into whose hands a publication of this sort may fall ».

9. Ibid., p. 180-181.

10. Merkle D., «Émile Zola devant la censure britannique », TTR, vol. 7, $\mathrm{n}^{\circ} 1$, 1994, p. 77-91.

11. Bourdieu P., La distinction, Paris, Éditions de Minuit, 1979, p. 49.

12. Ibid.

13. Ibid., p. 50.

14. Ibid., p. 142 .

15. (The) National Vigilance Association (NVA), Pernicious Literature. Debate in the House of Commons. Trial and Conviction for Sale of Zola's Novels. With 
Opinions of the Press, Strand, London, The National Vigilance Association, 1889 , p. 11.

16. Coustillas P. (dir. et intro.), Literature at Nurse, or Circulating Morals: A Polemic on Victorian Censorship, Sussex, The Harvester Press Limited, 1976, p. 48.

17. Merkle D., «Vizetelly \& Company as (ex)Change agent: Towards the Modernization of the British Publishing Industry », J. Milton et P. Bandia (dirs.), Agents of Translation, Amsterdam et Philadelphia, John Benjamins, 2009, p. 85106.

18. Thomas D., op cit., p. 2.

19. Bourdieu P., Ce que parler veut dire, Paris, Librairie Arthème Fayard, 1982, p. 69.

20. Des romans de Zola et de Flaubert, par exemple, sont considérés comme obscènes, sinon pornographiques.

21. O'Sullivan C., " Margin and the Third-person Effect in Bohn's Extra Volumes », D. Merkle, C. O'Sullivan, L. van Doorslaer et M. Wolf (dir.), The Power of the Pen: Translation and Censorship in Nineteenth-century Europe, Wien et Münster, Lit Verlag, 2010, p. 119-142.

22. Voir, à titre d'exemple, Merkle D., op. cit., 1994.

23. Voir Colligan C., «Obscenity and Empire: England's Obscene Print Culture in the Nineteenth Century » [thèse inédite], Kingston (ON), Queen's University, 2002, et Mullin K., « Pernicious Literature: Vigilance in the Age of Zola (18861899) », D. Bradshaw et R. Potter (dir.), Prudes on the Prowl: Fiction and Obscenity in England, 1850 to the Present, Oxford, Oxford University Press, 2013, pp. 30-51.

24. King G., Garden of Zola, New York, Barnes \& Noble, 1978, p. 228. King reproduit le principe qu'énonce Bowdler en 1823 : "If any word or expression is of such a nature that the first impression which it excites is an impression of obscenity, that word ought not be spoken, or written, or printed; and if printed, it ought to be erased » (ibid.). 
25. PAGÈs A., La bataille littéraire, Paris, Librairie Séguier, 1989, p. 13.

26. Voir Merkle D., op. cit., 1994.

27. Bourdieu P., op. cit., 1982, p. 69.

28. Bourdieu P., op. cit., 1979, p. 49.

29. Merkle D., "Germinal en Grande-Bretagne de 1884 à 1895 : de l'esthétique dominée à l'esthétique dominante », Cahiers naturalistes, nº 81, 2007, pp. 198-199.

30. La formule est de P. Bourdieu, op. cit., 1979, p. 49.

31. Bakker B., Correspondance, tome V 1884-1886, Montréal, Presses de l'Université de Montréal et Paris, CNRS, 1985, p. 186, lettre 121, note $2:$ « [L]e texte $\mathrm{a}[. .$.$] subi des coupures analogues à celles de l'édition allemande. »$

32. Pour plus de détails sur le parcours de Germinal en Grande-Bretagne de 1884 à 1895, voir MERKLE, op. cit., 2007.

33. Ibid., p. 204.

34. Bourdieu P., op. cit., 1979, p. 49.

35. Ibid.

36. Bonnetain P., Rosny J.-H., Descaves L., Marguerite P., Guiches G., Manifeste des Cinq : La Terre, à Émile Zola. En ligne : http://www.berlol.net/ chrono/des5.htm. Page consultée le 28 juillet 2015.

37. Du fait que la traduction de Salammbô produite par J. S. Chartres pour le compte de Vizetelly \& Co (1886) n'a pas été poursuivie par la ligue de moralité, nous n'en discutons pas dans cet article. Pour savoir plus sur les traductions concurrentes de cette œuvre, nous renvoyons à Atkinson J., «'The Most Thrilling and Fascinating Book of the Century': Marketing Gustave Flaubert in Late Nineteenth-Century England », K. MacDonald et C. Singer (dir.), Transitions in Middlebrow Writing, 1880-1930, Houndmills (Basingstoke, Hampshire), Palgrave 
MacMillan, 2015, p. 163-182 et à Merkle D., «M. French Sheldon, Translator of Gustave Flaubert's Salammbô: Transauthorship and the Mechanics of Censorship in Late-Victorian Britain », D. Merkle, C. O'Sullivan, L. van Doorslaer et M. Wolf (dir.), The Power of the Pen: Translation and Censorship in Nineteenthcentury Europe, Wien et Münster, Lit Verlag, 2010, p. 97-118.

38. Tsuzuki C., The Life of Eleanor Marx 1855-1898, London, Oxford University Press, 1967, p. 113.

39. Son conjoint de fait est Edward Aveling.

40. Simon S., Gender in Translation, Cultural Identity and the Politics of Transmission, London et New York, Routledge, 1996, p. 67.

41. Voir James H., "Gustave Flaubert », Madame Bovary, London, Appleton \& Company, 1902, p. v-xliii : H. James écrit au sujet de Madame Bovary et de l'Éducation sentimentale :

"Our complaint is that Emma Bovary, in spite of the nature of her consciousness and in spite of her reflecting so much that of her creator, is really too small an affair. Why did Flaubert choose, as special conduits of the life he proposed to depict, such inferior and in the case of Frédéric such abject human specimens? [...] but if he imagined nothing better for his purpose than such a heroine and such a hero, both such limited reflectors and registers, we are forced to believe it to have been by a defect of his mind. " et « Émile Zola » (1903), Veeder et Griffin (dir.), The Art of Criticism: Henry James on the Theory and the Practice of Fiction, Chicago, University of Chicago Press, 1986, p. 423-458.

42. Tsuzuki C., op. cit., p. 166-167. Un roman controversé de G. Moore est $A$ Mummer's Wife.

43. Voir Kapp Y., Eleanor Marx: Volume II, The Crowded Years (1884-1898), London, Lawrence and Wishart, 1976, p. 95 et Florence R., Marx's Daughters, New York, Dial Press, 1975, p. 41.

44. KAPP Y., op. cit., p. 97. 
45. Pour savoir plus sur les retraductions britanniques de Madame Bovary, voir Deane S., "Flaubert and the retranslation of Madame Bovary », Flaubert, Revue critique et génétique [En ligne], vol. 6, 2011, mis en ligne le 30 janvier 2012. URL : http://flaubert.revues.org/1538 Page consultée le 28 juillet 2015.

46. Ibid., p. 99. Florence (op. cit., p. 42) croit également que la traduction de Marx-Aveling est la première traduction de ce roman à paraître en Angleterre.

47. Flaubert écrit dans une lettre adressée à E. Duplan (12 juin 1862) que la gouvernante de sa nièce, Juliet Herbert, a fait la traduction. Mais incapable de trouver un éditeur qui accepte de la publier, il s'était déclaré « prêt à abandonner tout ». Deane S., op. cit., paragraphe 1.

48. Simon, op. cit., 1996, p. 67.

49. Marx-Aveling E., "Introduction », Madame Bovary, traduction d'E. MarxAveling, London, Vizetelly \& Co, 1886, p. ix.

50. Ibid., p. xv.

51. Tsuzuki, op. cit., p. 166.

52. Ibid.

53. Marx-Aveling E., op cit., p. xxii.

54. Cité par Kapp Y, op. cit. p. 97.

55. Ce qui aurait choqué le lecteur bien-pensant, c'est le comportement du Maître Guillaumin, alors que ce comportement masculin renforce l'idéologie marxiste de Marx-Aveling en ce qui concerne la valeur de la femme comme objet d'échange. $\mathrm{La}$ traductrice ne veut pas épargner au lecteur cette description minutieuse du matérialisme grossier du système capitaliste.

56. Ellis H., « Eleanor Marx II », Adelphi, 11, 1 octobre 1935, p. 34. 
57. Kapp Y., op. cit., p. 98 reproduit un extrait de la critique publiée par W. Sharp dans The Academy du 25 septembre 1886:

" Flaubert is, pre-eminently, an untranslatable writer. He is as Mrs. Aveling appropriately remarks in her preface, inimitable... and he is untranslatable, not because he writes perfect French, but because words are to him supremely significant - have a weight, an urgency of revelation so to speak, that is almost of necessity beyond the power of the translator to reproduce in an alien language. It is tolerably certain that no English version of Flaubert's novels will ever adequately reproduce the charm of that master's style. We must be content with translation that is at once faithful and entirely natural. Mrs. Aveling deserves credit for the way she has accomplished her task; and if again and again we fail to discern Flaubert in the version before us - it is not always her fault. »

58. Steiner G., Après Babel: Une poétique du dire et de la traduction, traduction de L. Lotringer, Paris, Albin Michel, 1978, p. 347. Le flaubertien G. FALConER ("Madame Bovary and the Translators", P. Bhatt (dir.), Significations: Essays in honour of Henry Schogt, Toronto, Canadian Scholars Press, 1997, 41-50), considère la traduction de Marx-Aveling comme une traduction très moderne. Il ne la considère aucunement comme une réécriture. Falconer reconnaît que la traductrice colle au texte de départ (mais y voit quelque chose de positif) et, délibérément ou par inadvertance, elle reproduit ainsi le désordre textuel de Flaubert. Il reconnaît aussi qu'elle fournit un modèle de traduction que ses successeurs ont par la suite imité. Il s'agit donc d'une traduction primaire. Étant donnée la «modernité » de sa traduction, il ne doit pas étonner que sa traduction soit anomale comparativement à d'autres traductions publiées par Vizetelly \& Co. pendant la même décennie.

59. Simon S., op. cit., p. 67. Y. KAPP (op. cit., p. 99) critique les faiblesses d'une traduction qui contient des gallicismes incompréhensibles (selon Kapp, attribuables à Paul Lafargue qui n'a pas toujours compris l'anglais et qui a donc fourni des réponses erronées aux questions posées par sa belle-sœur), et qui est criblée de petites défaillances.

60. Voir Merkle, op. cit., 1994, pp. 81-82; 2007, pp. 201-205, pour en savoir plus.

61. Voir Ibid., 2007, pp. 201-204. 
62. Ibid.

63. Anonyme, «Vizetelly and Zola : The Paper Which First Introduced Zola to the English Masses », Star (2 November), 1888, p. 2.

64. Speirs D. et Portebois Y., Mon cher Maître, lettres d'Ernest Vizetelly à Émile Zola, Montréal, les Presses de l'Université de Montréal, 2002, p. 142, lettre 46.

65. Ibid., p. 95, lettre 20 .

66. King G., op. cit., p. 427.

67. Pour en savoir plus, voir Merkle D., « Secret Literary Societies in Late Victorian England ", M. Tymoczko (dir.), Translation, Resistance, Activism, Amherst et Boston, University of Massachussets Press, 2010, p. 108-128 et Merkle D., « The Lutetian Society », TTR, vol. 16, n 2, 2003, pp. 73-101.

68. Bourdieu P., op. cit., 1979, p. 50.

69. O’Sullivan C., op. cit.

70. Speirs D. et Portebois Y., op cit., p. 129, lettre 40, en date du 11 juillet 1894. Le promoteur semble avoir été Jean de Mattos, domicilié à Paris.

71. Ibid., p. 140, lettre 46. Voir également, p. 131, lettre 40, note 1.

72. Ibid., p. 131 , lettre 40 , note 1 .

73. Smithers a fondé en 1896 le périodique The Savoy, dont l'éditeur fondateur était Arthur Symons, un des traducteurs de la Lutetian Society. Dans Publisher to the Decadents, (Pennsylvania Park, The Pennsylvania State University Press, 2000), J. G. Nelson affirme que Leonard Smithers était le véritable dirigeant de la Lutetian Society, assisté du traducteur et journaliste Alexander Teixeira de Mattos, un de ces amis. Ce dernier a épousé Lily Wilde, la veuve du frère d'Oscar Wilde. Leonard Smithers fut le seul éditeur londonien à oser publier les œuvres de Wilde (p. 95). 
74. Ellis H., «Introduction », Germinal, London, J. M. Dent \& Sons Ltd, 1933 : «It is [...] a satisfaction for me to know that I have been responsible, however inadequately, for the only complete English version of his wonderful book, 'a great fresco,' as Zola himself called it, a great prose epic, as it has seemed to some, worthy to compare with the great verse epics of old» (p. viii).

75. O'Sullivan C., "Margin and the third-person effect », op. cit., p. 120. Reprise à bon escient par O'Sullivan, la notion de " margin » est d'abord conçue par A. Lefevere ("Translations and Other Ways in Which One Literature Refracts Another », Symposium, vol. 38, n 2, 1984, p. 128).

« [...] you can, in theory, say anything you want, any way you want. In practice, though, if you want to be listened to at all, you will have to say it within a certain margin, and that margin, which grows wide or narrower in history, is drawn by those I would call patrons, ...] all powers that (happen to) be and that are able to commission, foster, encourage, hinder, censor, burn the production of texts, original or translated. These powers, churches, political parties, publishers and their editors, radio and television programmers, draw the margin and they are also able to make it stick, more or less completely in totalitarian societies, less so in non-totalitarian ones. The margin does, of course, coincide with the patrons' world view, and they are able to draw and enforce it because they can dispense to writers, to a certain extent, both economic subsistence and a certain social niche, more or less prestigious, or withhold both from them. »

76. Voir Merkle D., « Towards a Sociology of Censorship: Translation in the LateVictorian Publishing Field », M. Wolf (dir.), Übersetzen - Translating - Traduire: Towards a "Social Turn"?, Wien et Münster, Lit Verlag, 2006, p. 35-44.

77. Merkle D., op. cit., 2010.

78. Hjørnager Pedersen V., "Self-censorship in Victorian Translations of Hans Christian Anderson », T. Seruya et M. L. Moniz (dir.), Translation and Censorship in Different Times and Landscapes, Newcastle, Cambridge Scholars Publishing, 2008, p. 308-318. 